
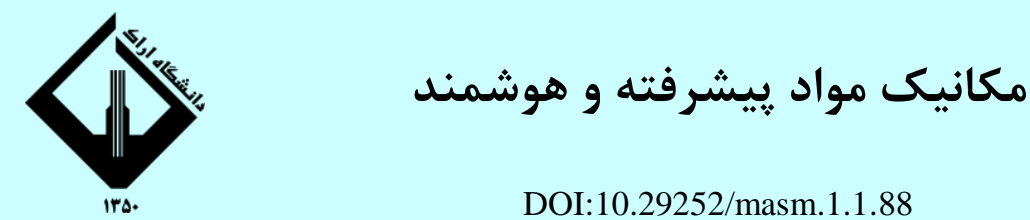

$$
\begin{aligned}
& \text { مطالعه فر آيند تغيير شكل پيلاستيك شديد بر مبناى آناليز حساسيت اىفست } \\
& \text { جهت بهينهسازى يار امتر ها } \\
& \text { سيد حسن بطحائى الف* } \\
& \text { الف" دانشجوى كارشناسىارشد، كروه مهندسى ساختوتوليد ، دانشكده مهندسى مكانيك، دانشكاه تربيت مدرس، تهران، ايران } \\
& \text { h.bathaee@modares.ac.ir }
\end{aligned}
$$

\begin{tabular}{|c|c|}
\hline جـيده & وازَان كليدى \\
\hline 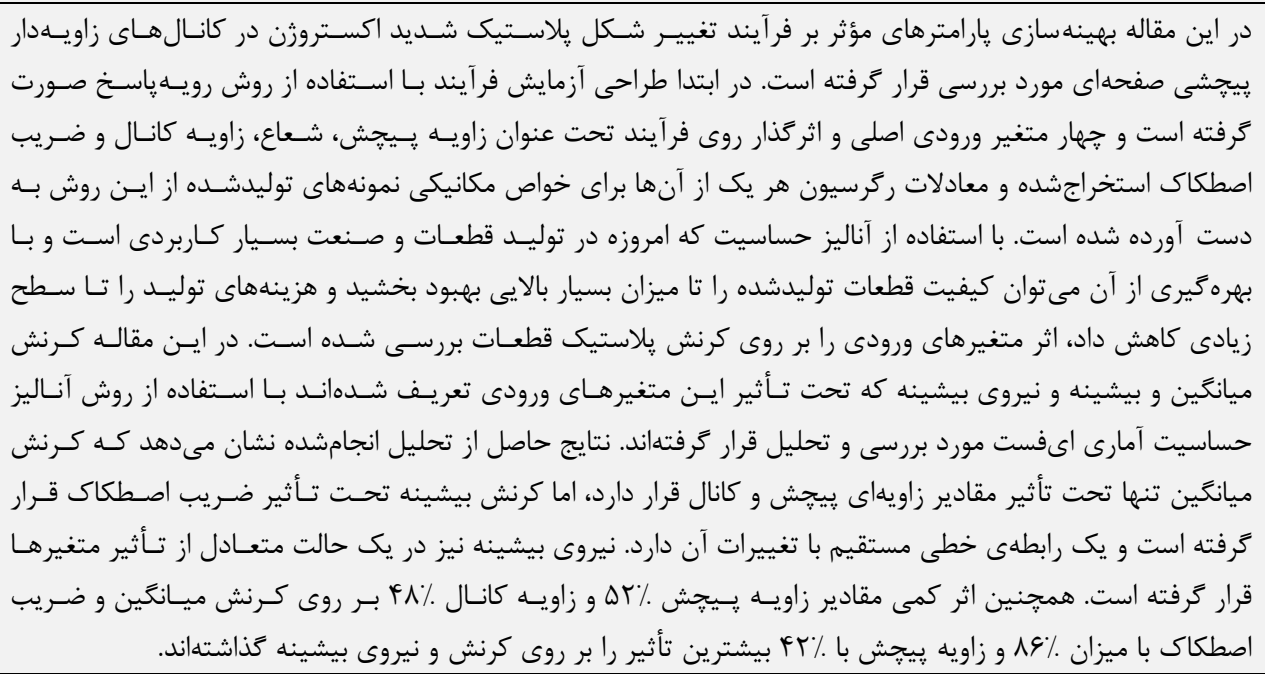 & 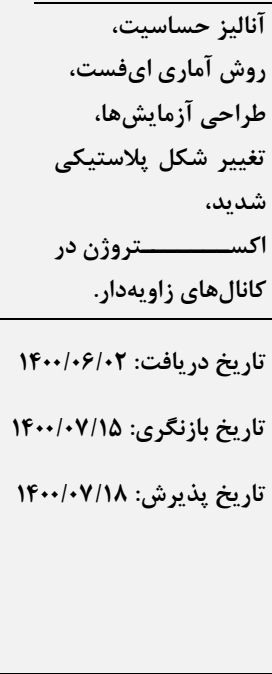 \\
\hline
\end{tabular}

\title{
Study of severe plastic deformation process based on E-fast sensitivity analysis to optimize parameters
}

\author{
Seyed Hasan Bathaee ${ }^{\text {a* }}$
}

${ }^{a}$ MSc. Student, Department of Mechanical Engineering, Tarbiat Modares University, Tehran, Iran

\section{K E Y W O R D S}

Sensitivity Analysis, E-fast Statistical Method, Design of experiments, Extreme plastic deformation, Extrusion in angled channels.

Received: August 24, 2021 Revised: October 07, 2021 Accepted: October 10, 2021

\begin{abstract}
A B S T RAC T
In this paper, the optimization of effective parameters on the process of severe plastic extrusion deformation in the torsional angular channels of the plate is investigated. Initially, the process test was designed using the response procedure method, and four main and influential input variables on the process, torsion angle, radius, channel angle, and coefficient of friction, were extracted, and the regression equations of each for the mechanical properties of the samples produced by this method. Using sensitivity analysis, which is very useful in the production of parts and industry today, and by using it, the quality of manufactured parts can be greatly improved and production costs can be reduced to a large extent, the effect of input variables on plastic strain Parts checked. In this paper, the mean and maximum strain and maximum force, which are defined under the influence of these input variables, have been investigated and analyzed using the e-Fast statistical sensitivity analysis method. The results of the analysis show that the mean strain is affected only by the values of torsional and channel angles, but the maximum strain is affected by the coefficient of friction and has a direct linear relationship with its changes. The maximum force is also in a balanced state from the effect of the variables. Also, the quantitative effect of torsion angle of $52 \%$ and channel angle of $48 \%$ on mean strain and coefficient of friction with $86 \%$ and torsion angle with $42 \%$ had the greatest effect on strain and maximum force.
\end{abstract}




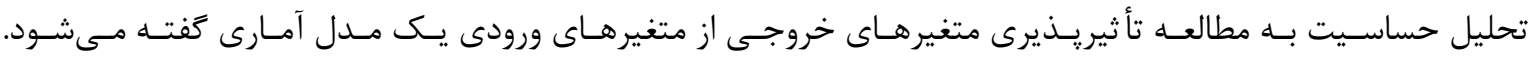

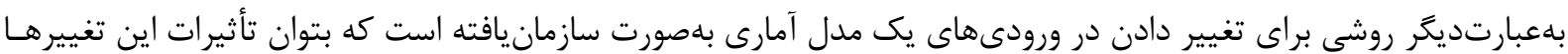

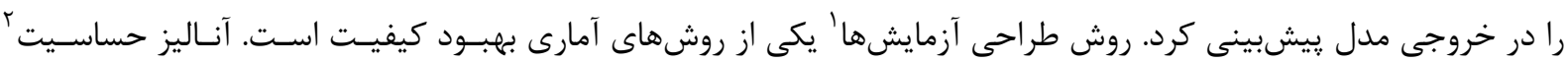

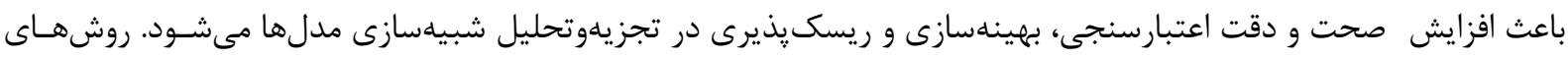

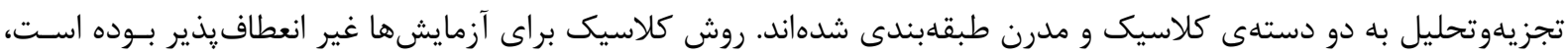

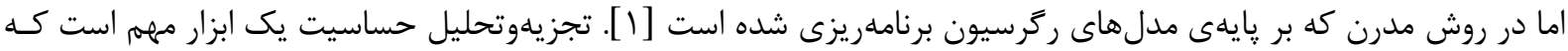

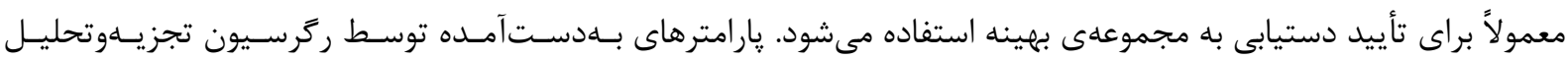

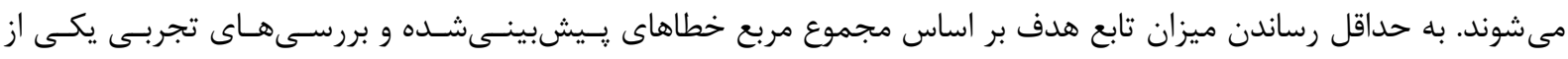

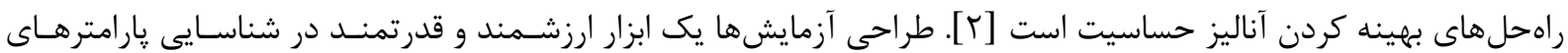

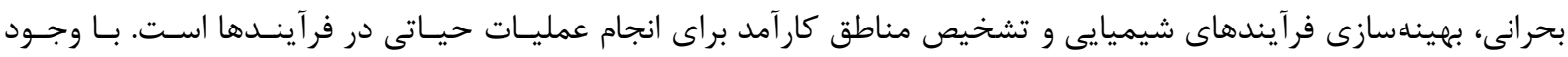

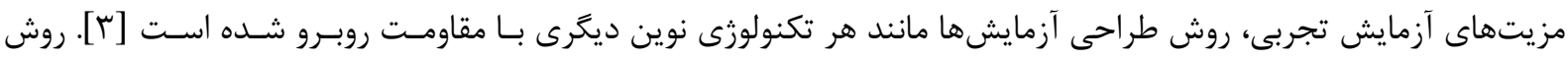

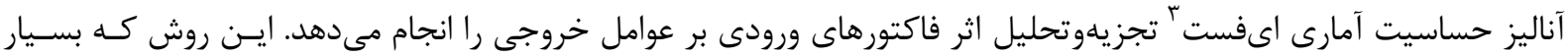

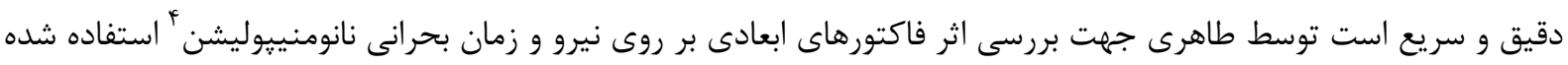

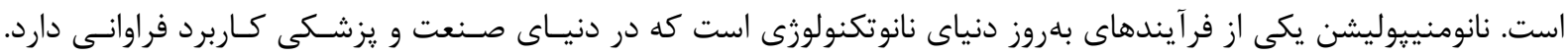

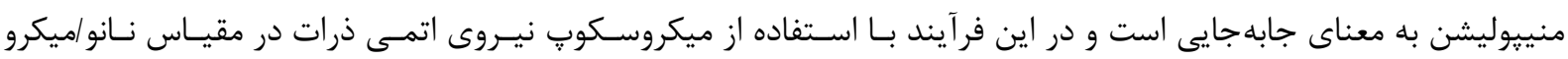

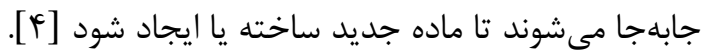

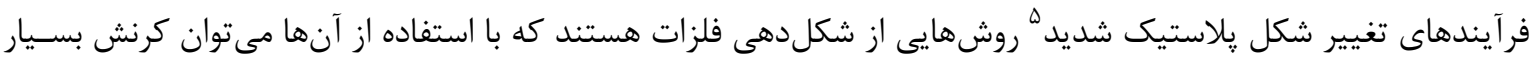

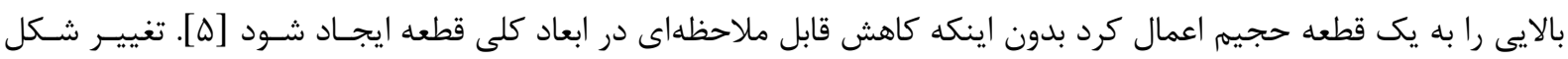

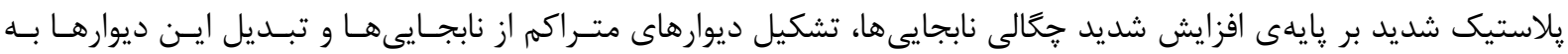

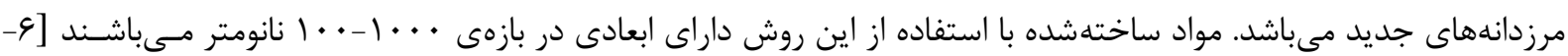

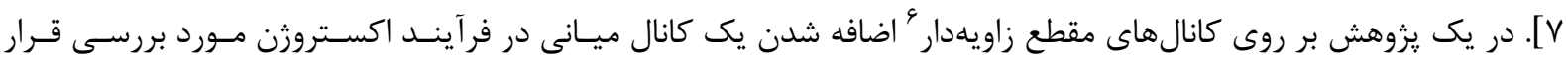

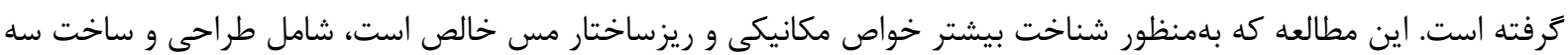

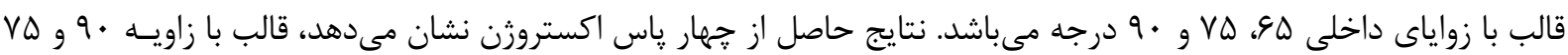

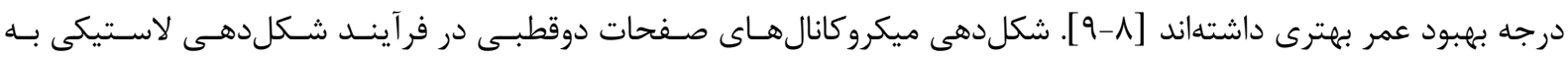

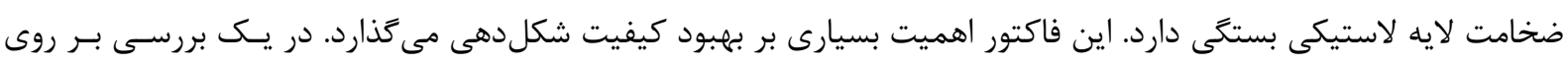

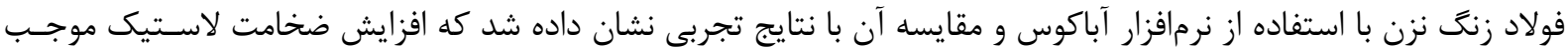

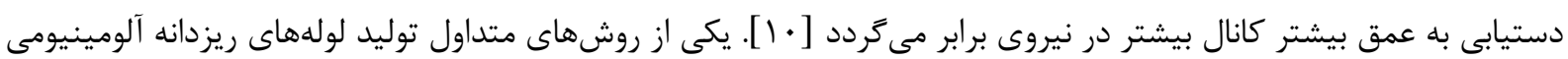

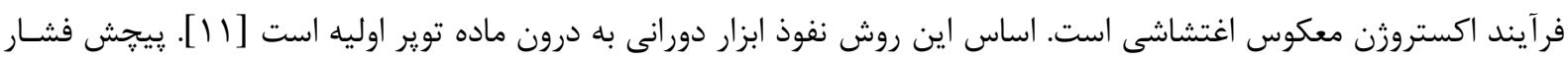

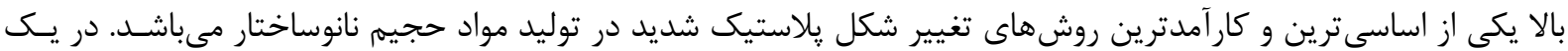

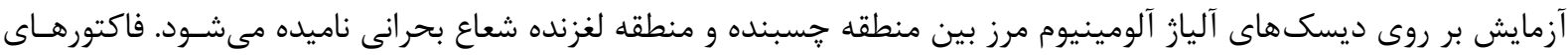

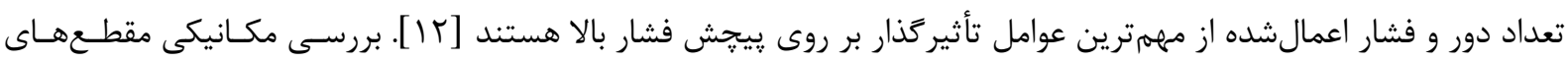

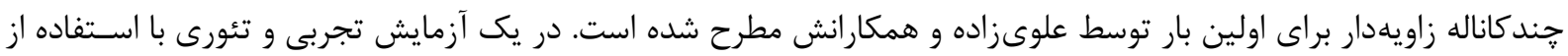

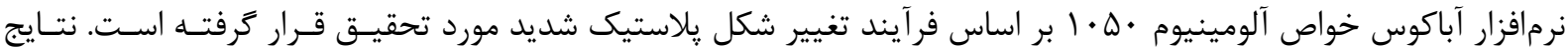

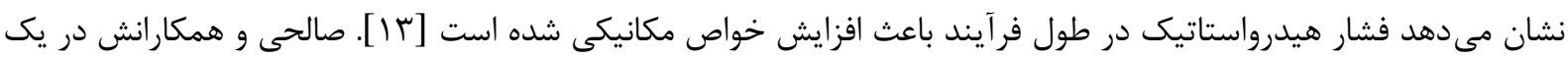

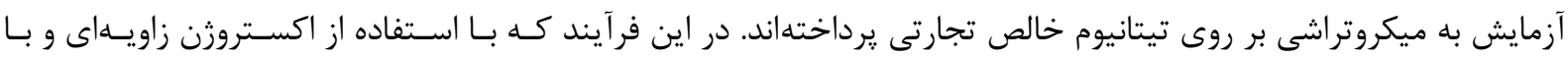

\footnotetext{
${ }^{1}$ DOE: Design of Experiments

2 Sensitivity Analysis

${ }^{3}$ E-fast: Extended Fourier amplitude sensitivity test

${ }^{4}$ Nanomanipulation

${ }^{5}$ SPD: Severe Plastic deformation

${ }^{6}$ ECAP: Equal channel angular extrusion
} 


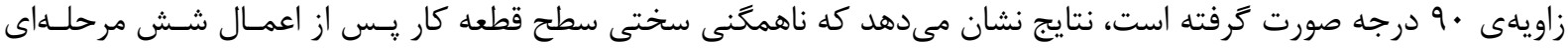

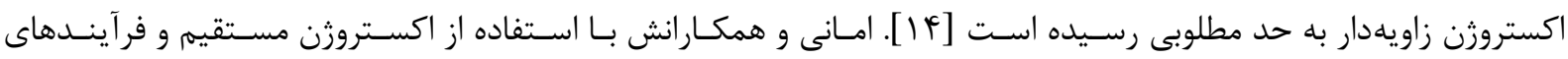

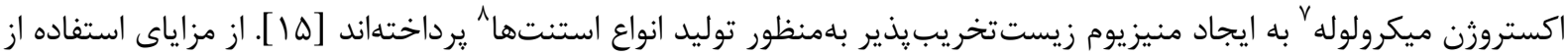

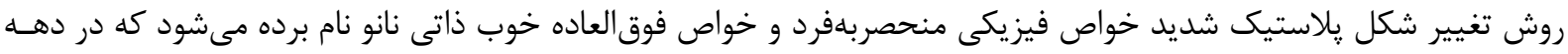

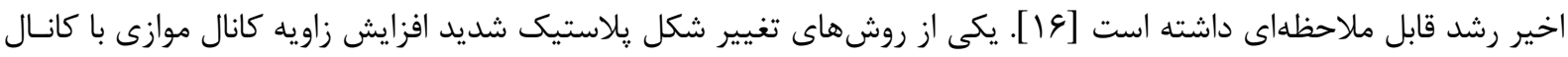

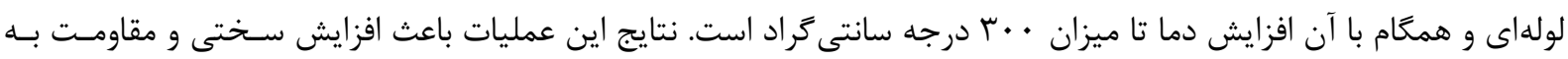

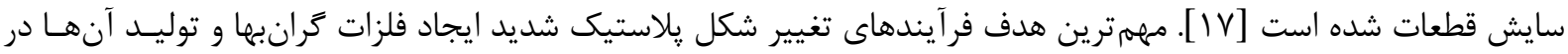

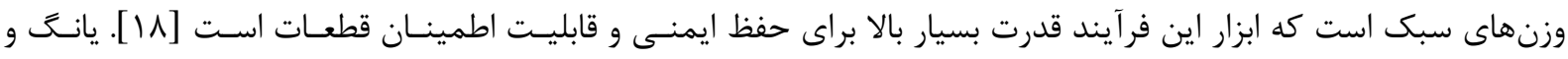

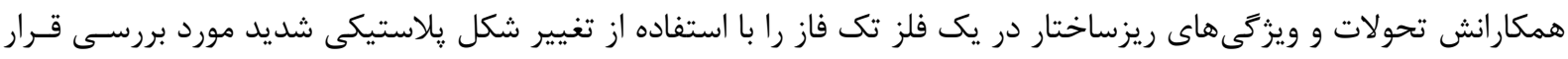

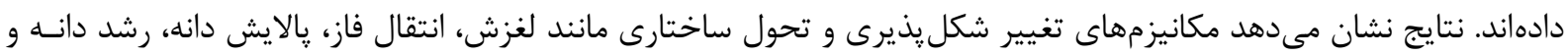

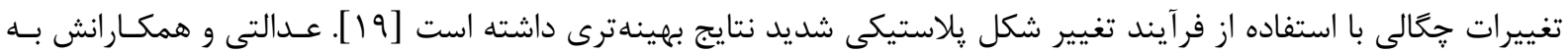

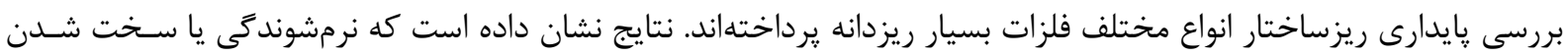

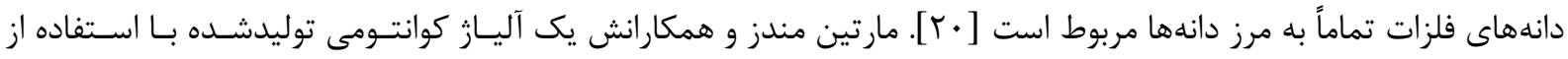

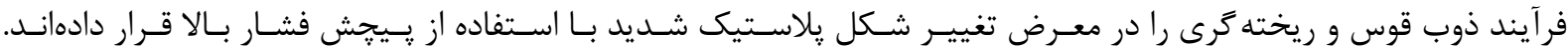

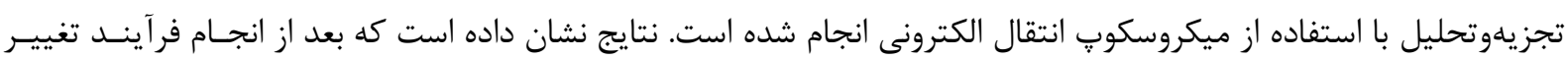

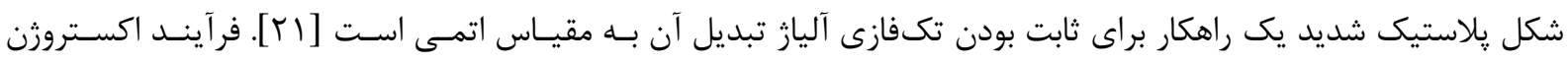

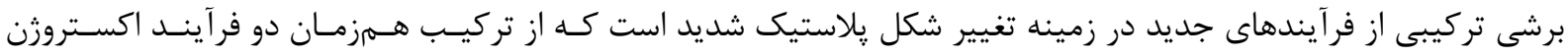

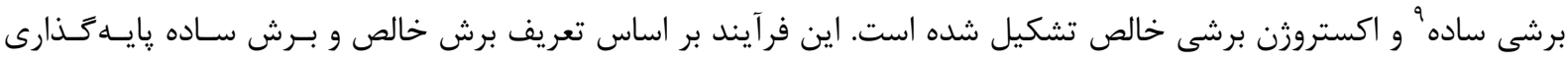

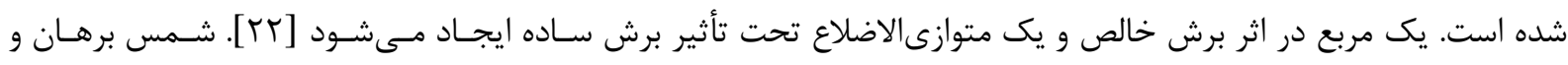

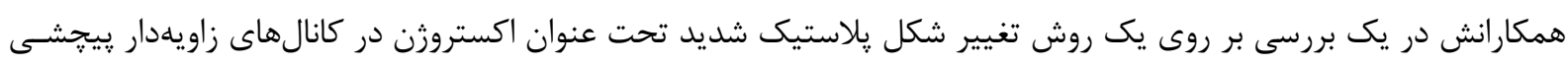

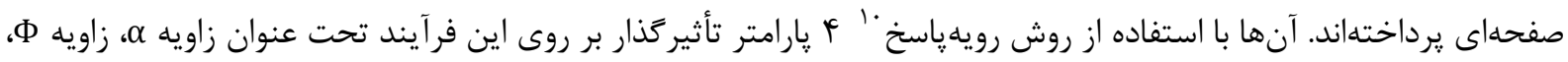

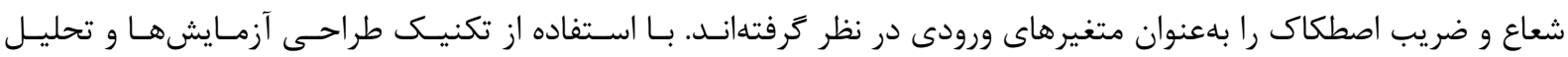
ركرسيون به شبيهسازى و تحليل يرداختهاند [rr]

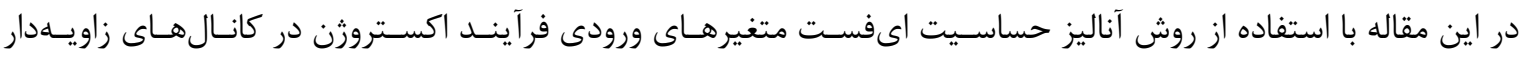

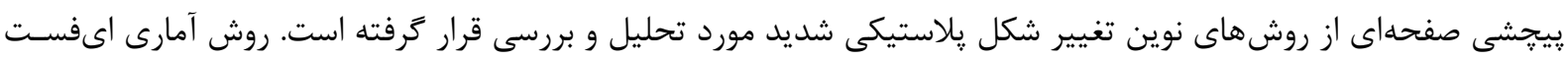

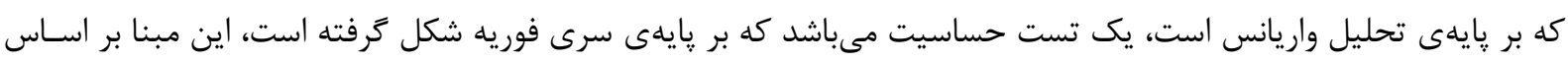

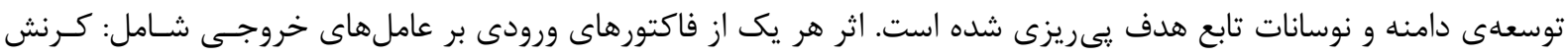

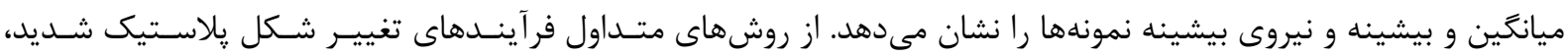

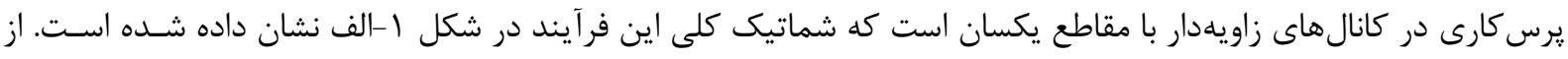

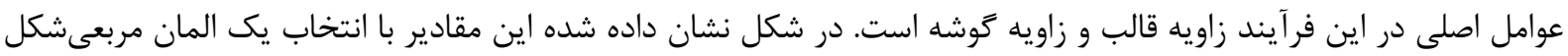

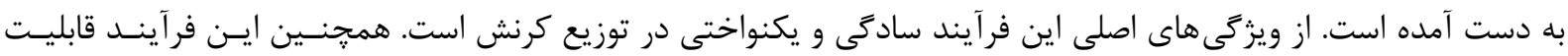

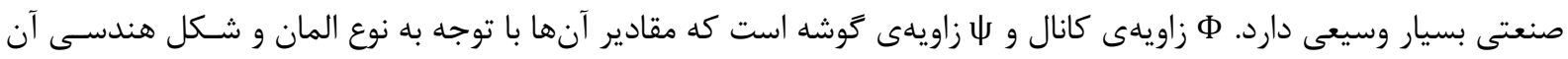

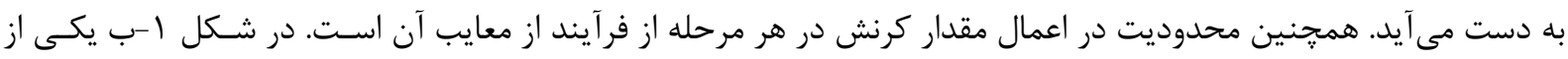

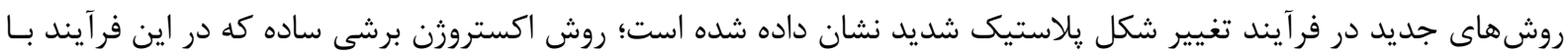

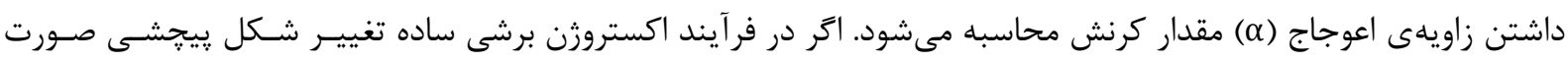

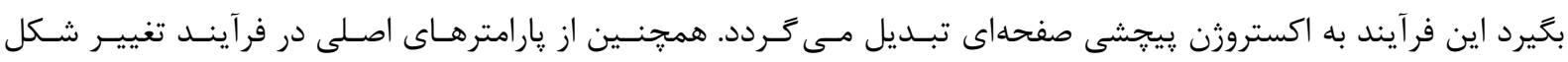

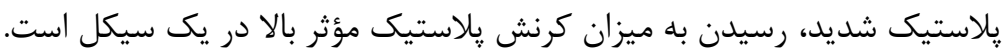

\footnotetext{
${ }^{7}$ Micro tube

${ }^{8}$ Stents

${ }^{9}$ Simple shear extrusion

${ }^{10}$ Regression Analysis
} 


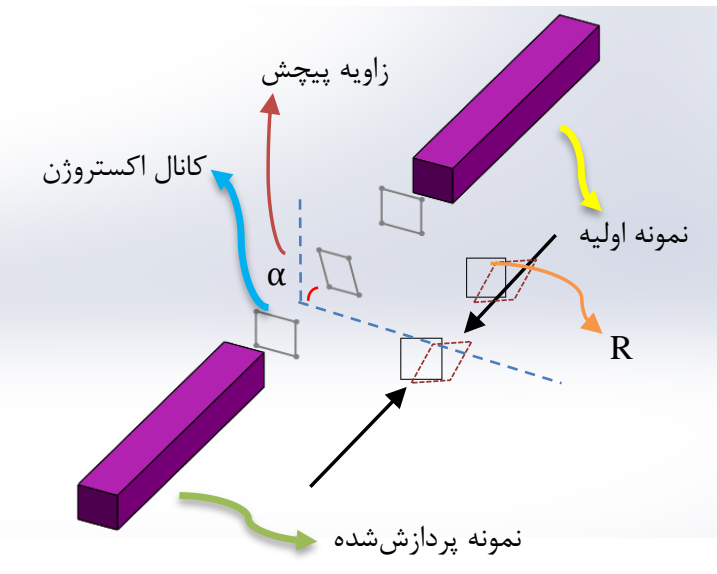

ب

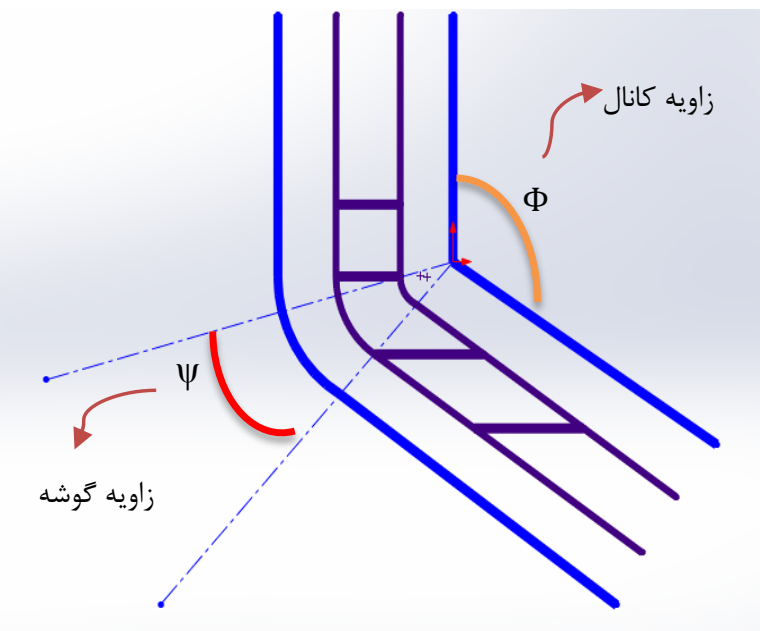

الف

شكل ا شماتيك فر آيند تغيير شكل هِلاستيك شديد، الف) شماتيك فر آيند كانال هاى مقطع زاويهدار با زاويه كانال و زاويه كوشه، ب) شماتيك فر آيند اكستروزن برشى ساده

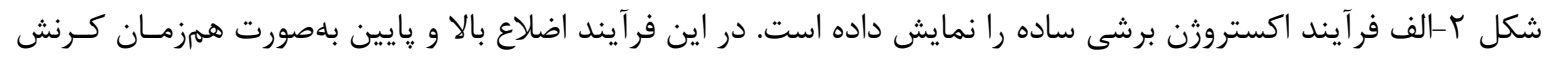

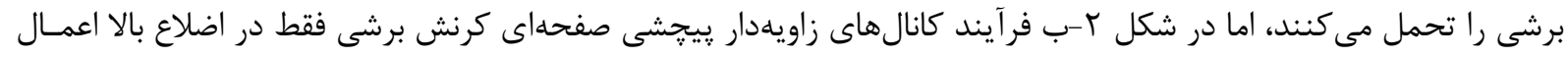

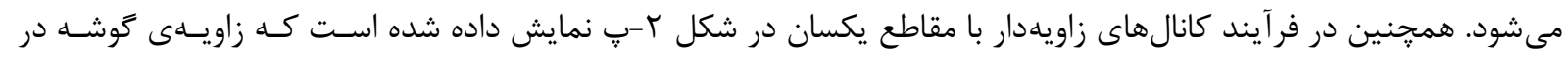

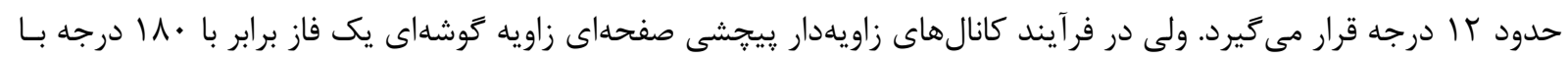

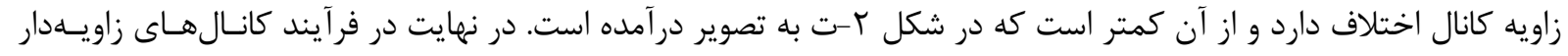

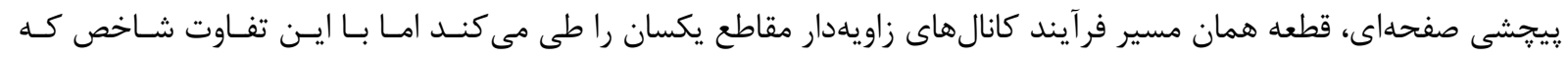

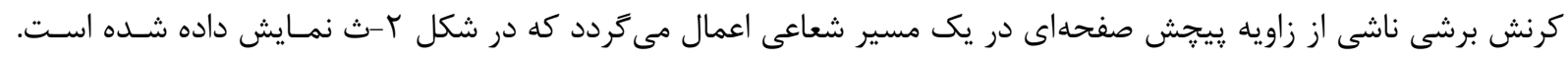

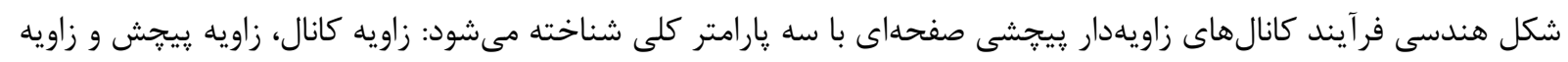

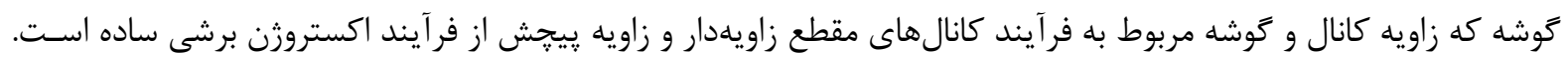

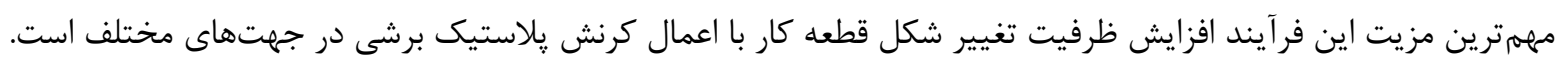

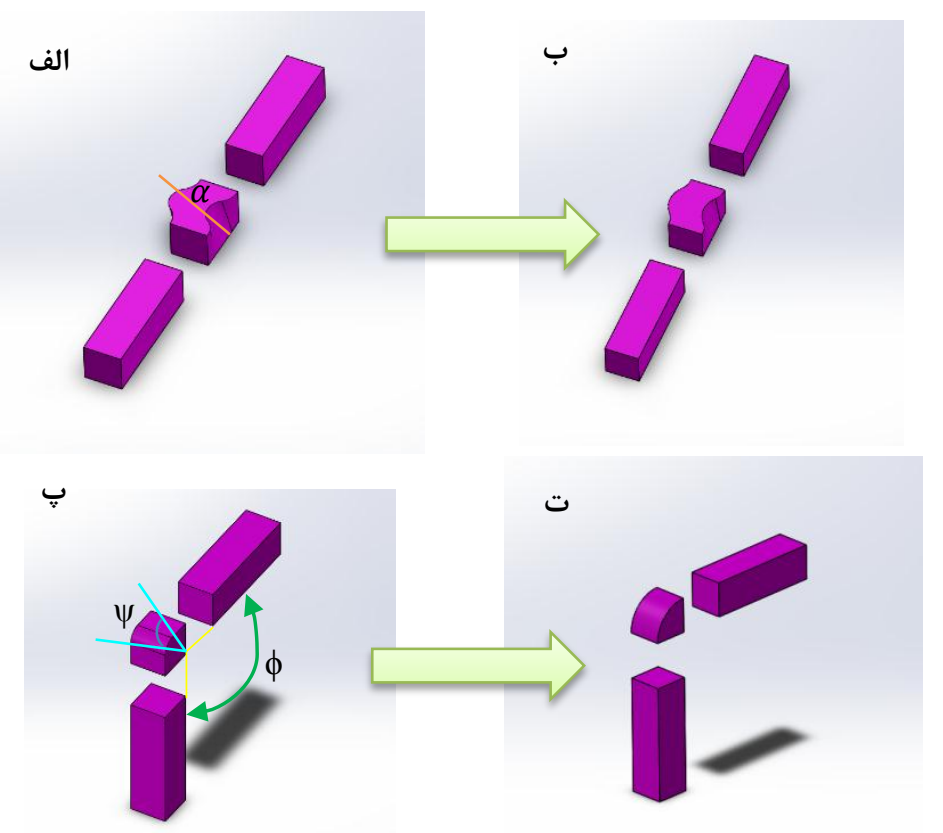




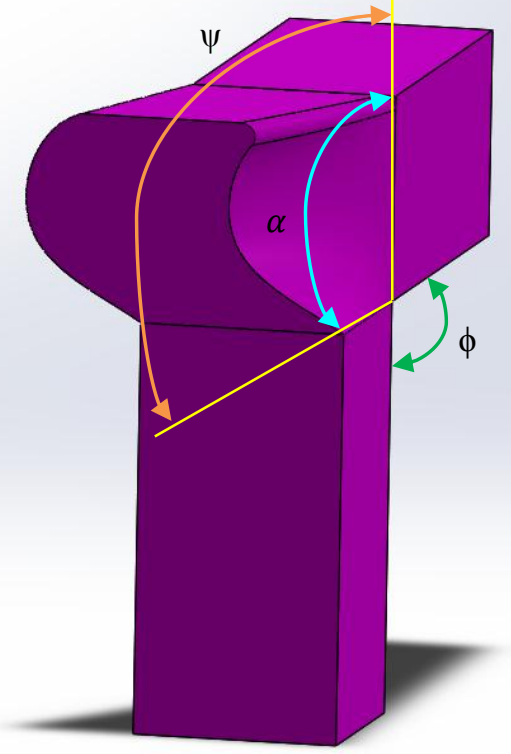

شكل r شماتيك فر آيندهاى اكستروثن يِيجشى صفحهاى الف) دوجهته، ب) يكجهته، اكستروزن در كانالهاى زاويهدار هم مقطع با

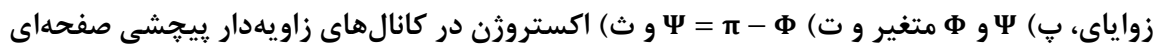

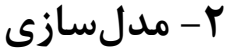

در اين مقاله مدلسازى از دو بخش تشكيل شده است: الف) طراحى آزمايشها با استفاده از روش رويهياسخ

$$
\text { ب) بررسى آناليز حساسيت آمارى ایىفست }
$$

r-1- طراحى آزمايشها (تكنيك رويه ياسخ)

يكى از بهترين تكنيكهاى بهينهسازى، استفاده از روش رويهياسخ است. همجنين براى توصيف و شـرح انسواع فرآينـدهاى

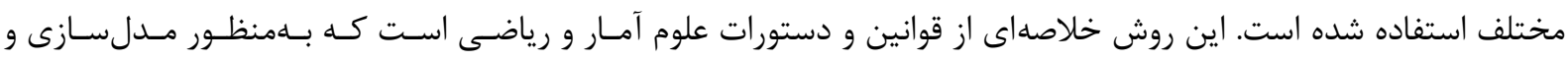

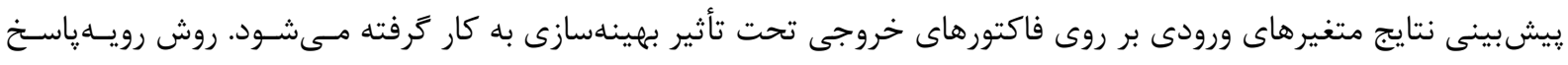

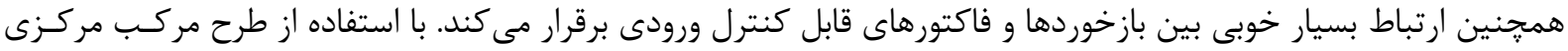

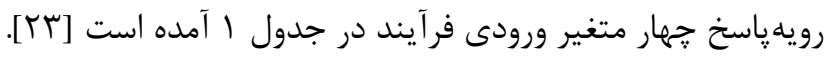

\begin{tabular}{|c|c|c|c|c|}
\hline كمينه & بيشينه & واحد & علامت & متغير \\
\hline • & f. & $\circ$ & $\alpha$ & زاويه پِيجش \\
\hline$\cdot$ & r & $\mathrm{mm}$ & $\mathrm{R}$ & شعاع \\
\hline$\Delta \cdot$ & $1 \pi$. & $\circ$ & $\Phi$ & زاويه كانال \\
\hline$\cdot / 1$ & $\cdot / \mu$ & - & $\mu$ & ضريب اصطكاى \\
\hline
\end{tabular}

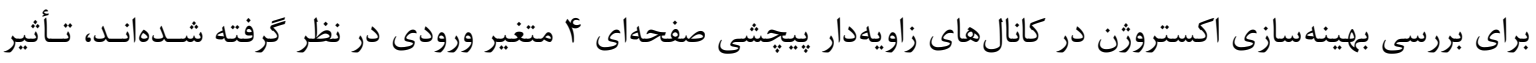

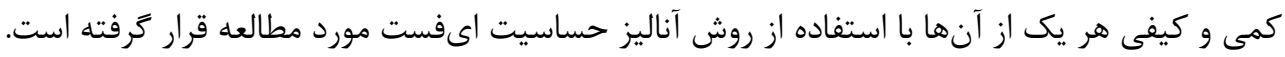




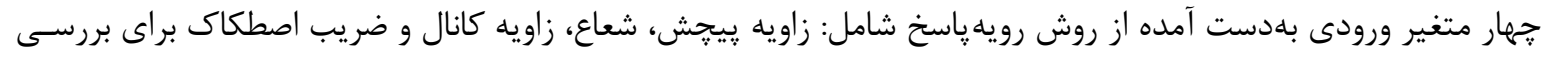

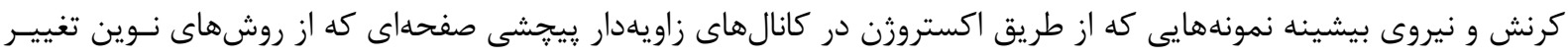

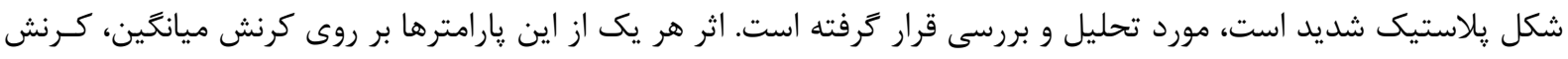

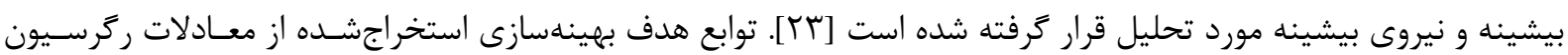

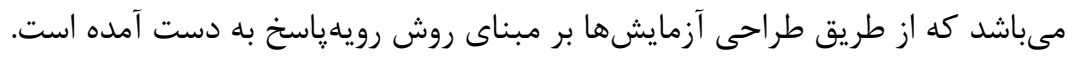

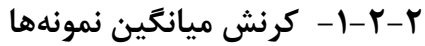

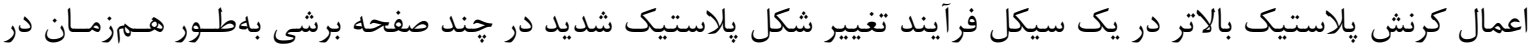

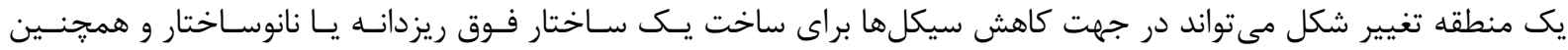

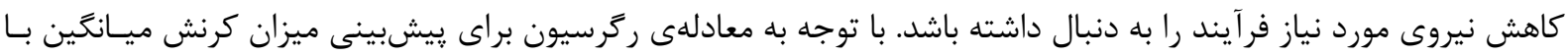

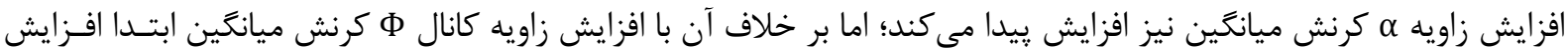

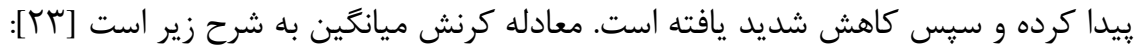

$U_{\text {ave }}=1.32526+0.27862 \alpha-0.23757 \Phi$

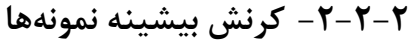

هر جه ميزان كرنش در يك سيكل فرآيند تغيير شكل پِلاستيك شديد بالاتر باشد، سرعت ريزدانهشـدن سـريعتـر و تعـداد

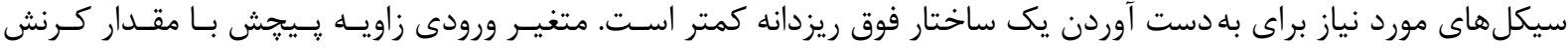

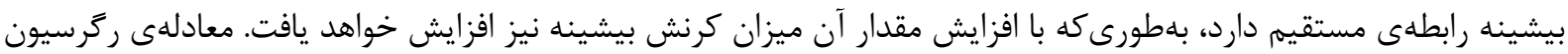

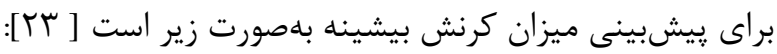

$U_{\max }=1.74242+0.282936 \alpha-0.186018 \Phi+1.1022466 \mu-0.106973 \Phi^{2}-(0.163493 \times \alpha \times \Phi)$

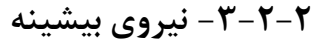

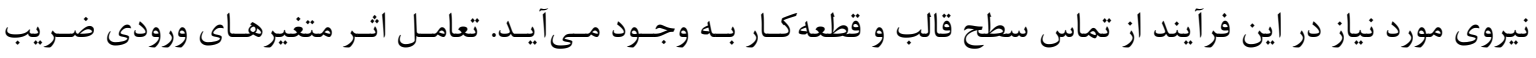

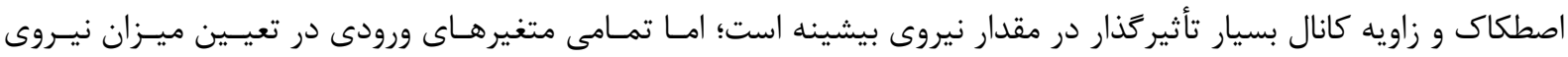
بيشينه مؤثر هستند. معادلهى ركرسيون براى بيشبينى نيروى بيشينه به شرح زير است [برآ]:

$F_{\text {max }}=18691.1+2458 \alpha-937.695 R-2908.89 \Phi+2337.72 \mu-(900.047 \times \Phi \times \mu)$

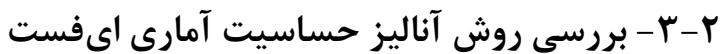

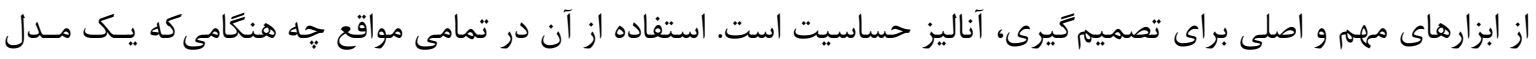

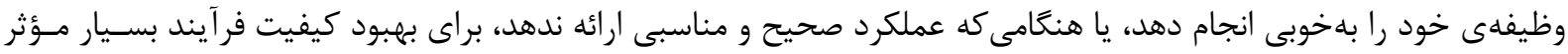

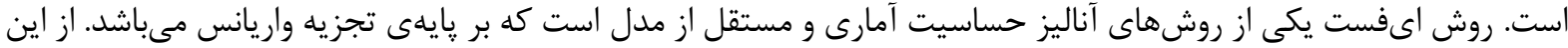

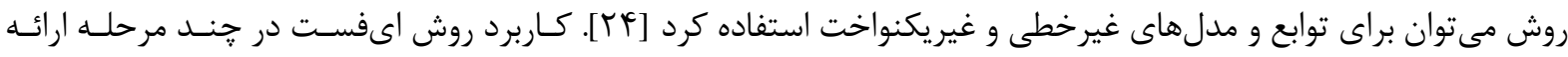

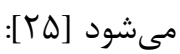

الف) مرحله اول: انتخاب دقيق فر كانسها است. در اين مرحله مجموعهاى از n فر كانس وجود دارد كه بايد از ايـن مجموعـهـ

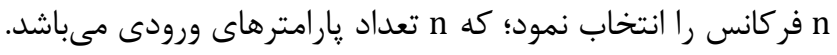

ب) مرحله دوم: بهدلخواه يك فركانس از مجموعهى فركانسها انتخابشده و به پارامترهاى ورودى نسبت داده مىشود.

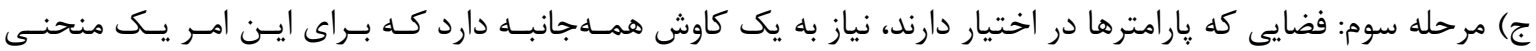


د) مرحله جهارم: انديس هاى حساسيت مرتبه اول و مرتبه كلى بهوسيلهى يك ابزار بسيار مهم بهنام تحليل فوريه محاسـبه

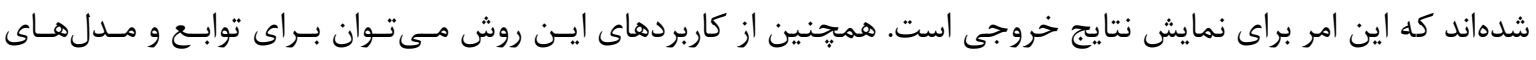

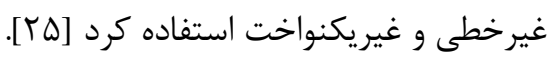

لازم است يكى مجموعه از فر كانس ورودى بلهطور خطى مستقل انتخاب كردد. معادلات (أ) و (b) شرطهـاى ايـن مجموعـهـ

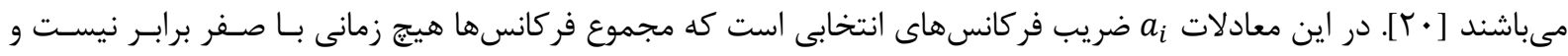

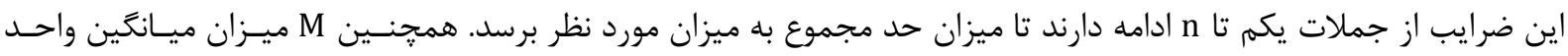

$\sum_{i=1}^{n} a_{i} \omega_{i} \neq 0$
$\sum_{i=1}^{n}\left|a_{i}\right| \leq M+1$

فر كانس هاى $\}$

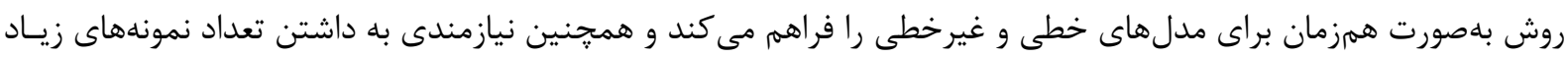

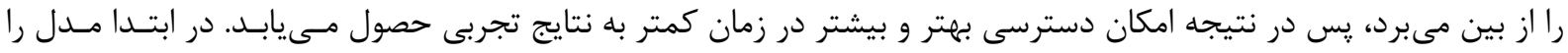

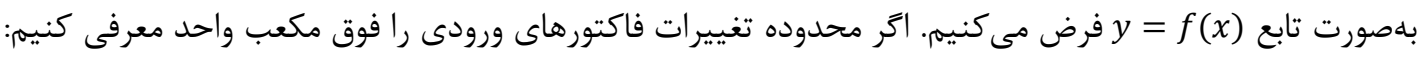
$K^{n}=\left\{\left(x \mid 0 \leq x_{i} \leq 1 ; i=1.2 .3 \ldots . n\right)\right\}$

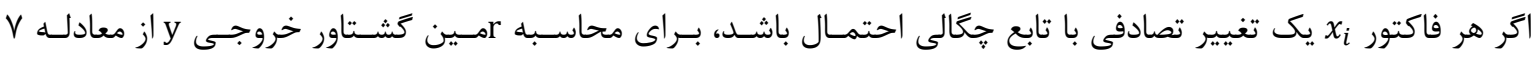

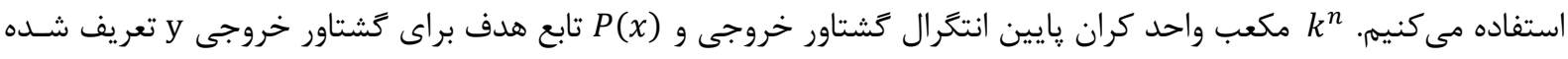

$\left\langle y^{(r)}\right\rangle=\int_{K^{n}} f^{r}\left(x_{1} \cdot x_{2} \ldots . x_{n}\right) P(x)=P\left(x_{1} \cdot x_{2} \ldots \cdot x_{n}\right) d x$

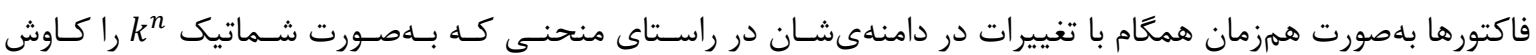

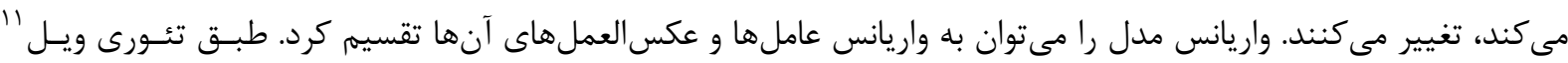

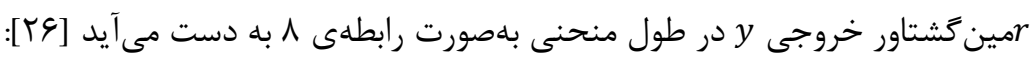

$\bar{y}^{(r)}=\lim _{\tau \rightarrow \infty} \frac{1}{2 \tau} \int_{-\tau}^{\tau} f\left[x_{1}(s) \cdot x_{2}(s) \ldots . x_{n}(s)\right] d s$

تئورى ويل بر اين دلالت دارد كه:

$\left\langle y^{(r)} \cong \bar{y}^{(r)}\right\rangle$

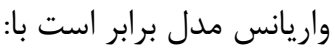

$D=y^{(2)}-\left\langle y^{(1)}\right\rangle^{2} \cong \bar{y}^{2}-\left(\bar{y}^{(1)}\right)^{2}$

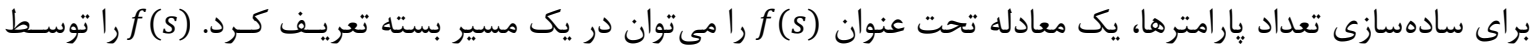

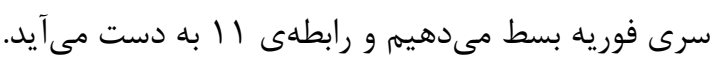

$f(s)=\sum_{j=-\infty}^{\infty}\left\{A_{j} \cos j s+B_{j} \operatorname{sinj} s\right\}$

ضرايب فوريه

$A_{j}=\frac{1}{2 \pi} \int_{-\pi}^{\pi} f(s) \operatorname{cosj} s d s$

$B_{j}=\frac{1}{2 \pi} \int_{-\pi}^{\pi} f(s) \operatorname{sinj} s d s$ 
در شكل r مكانيزم روش آناليز حساسيت ایىفست نشان داده شده است، همجنين مزيت و عيب عمدهى آن نشان داده

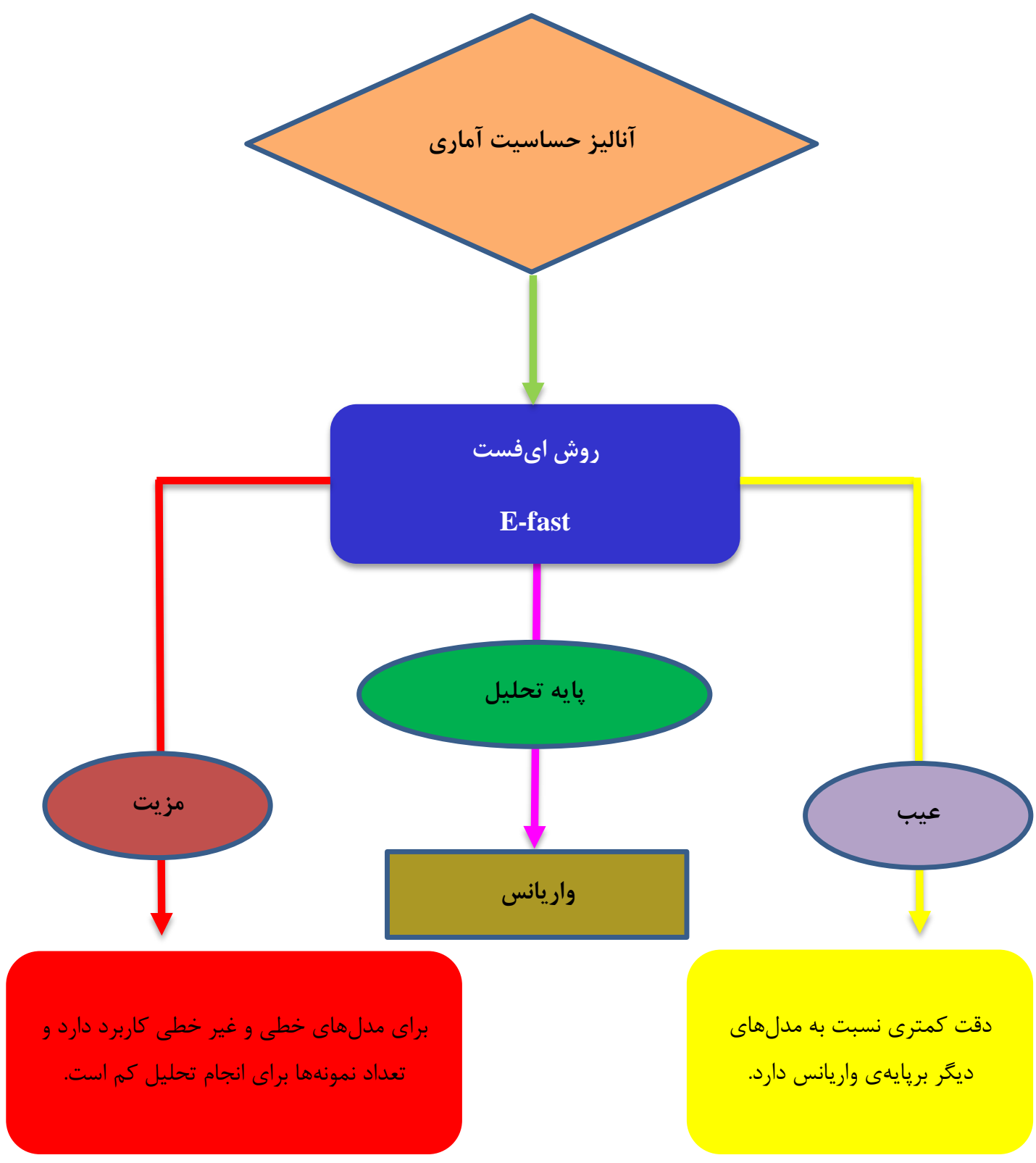

شكل r تحليل روش آناليز حساسيت ایىفت

r- شبيهسازى

در اين بخش به بررسى نمودارهاى كرافيكى آناليز حساسيت يرداخته شده و اثرات هر يك از متغيرهاى ورودى جدول 1 بر بر إن

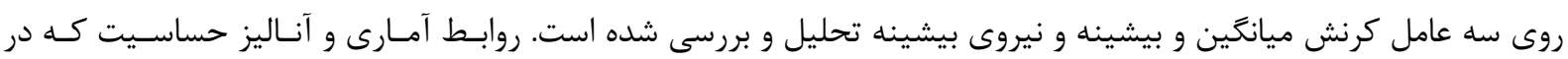

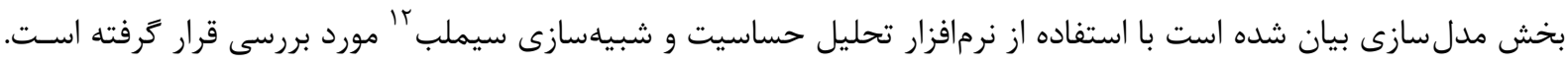

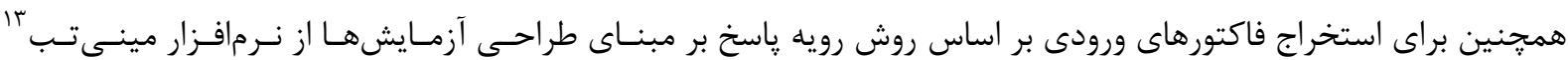
بهرهزيرى شده است. 


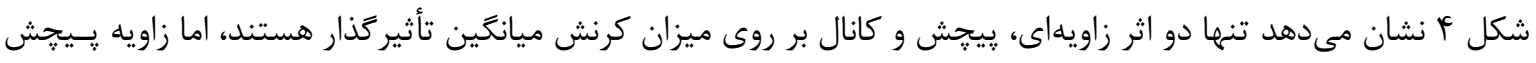

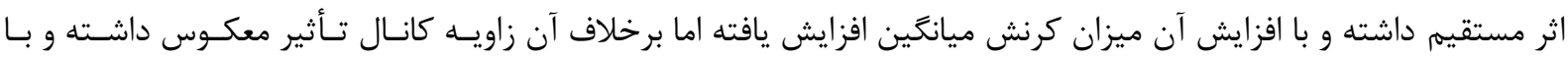

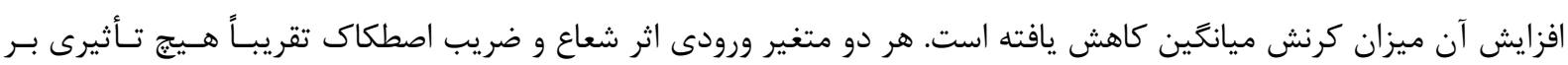

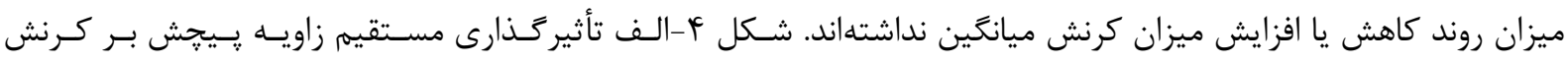

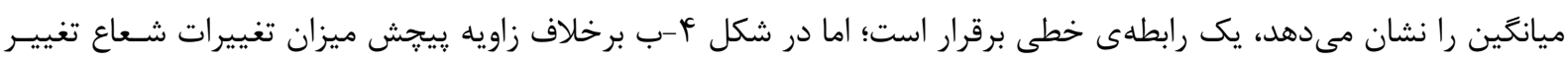

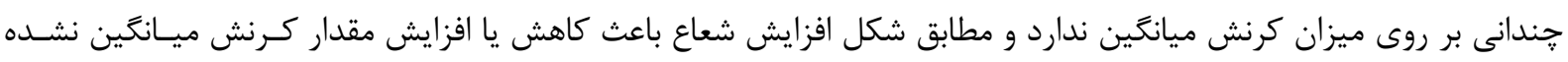

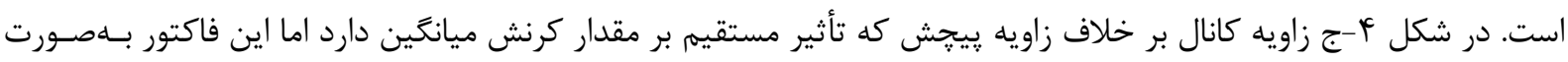

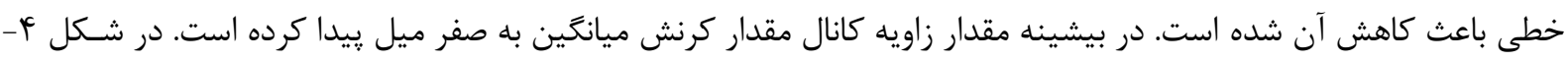

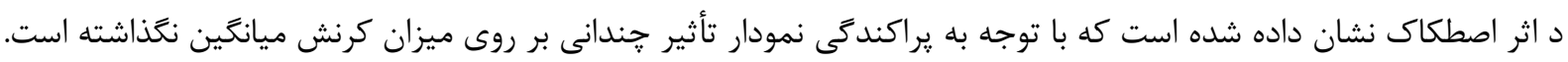

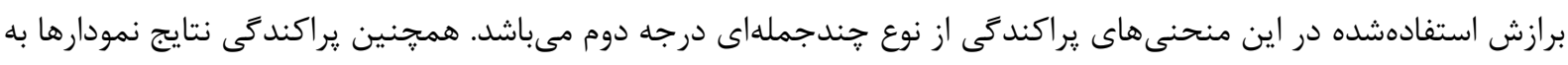

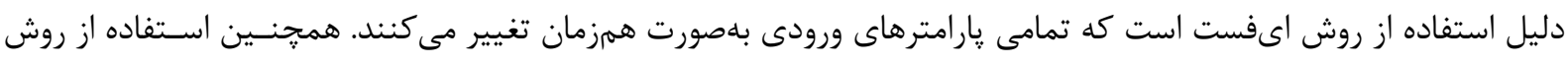

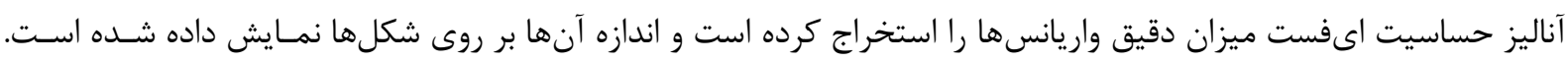

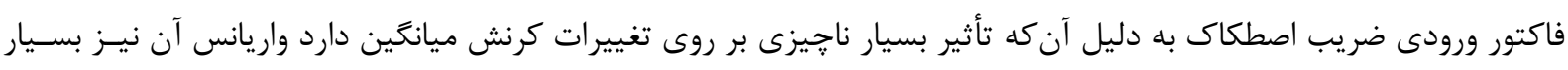

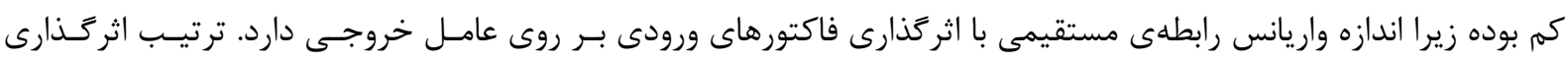

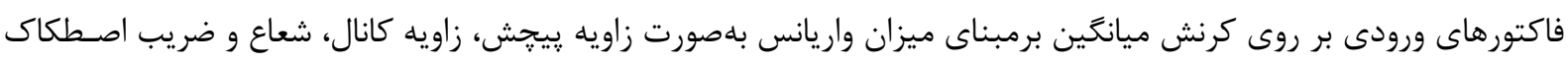

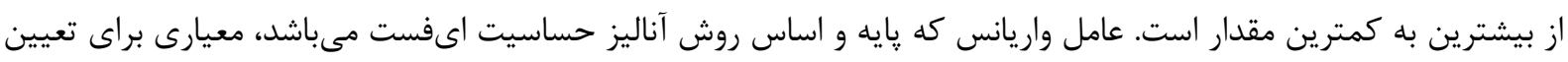

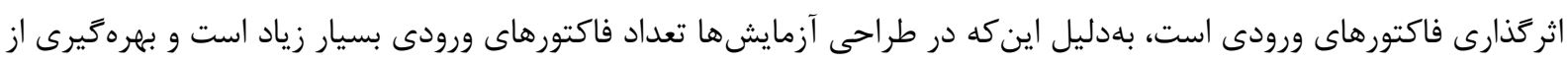

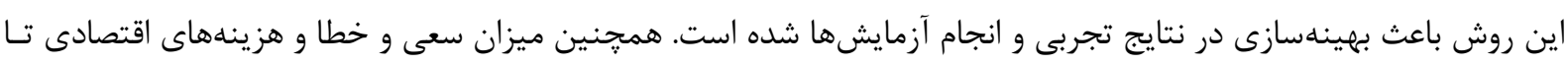

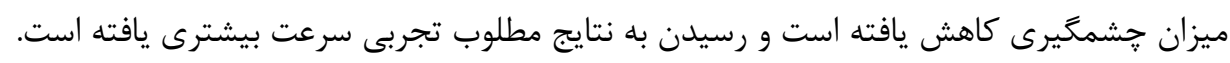

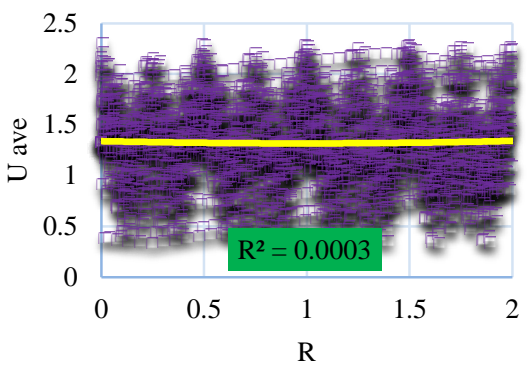

ب) اثر شعاع

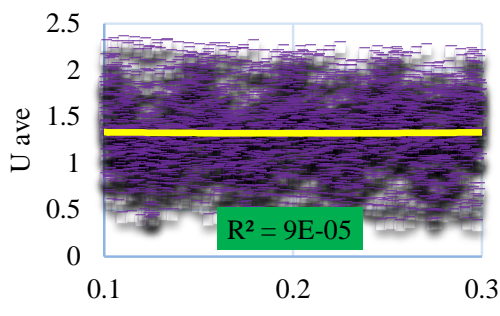

$\mu$

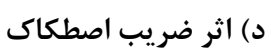

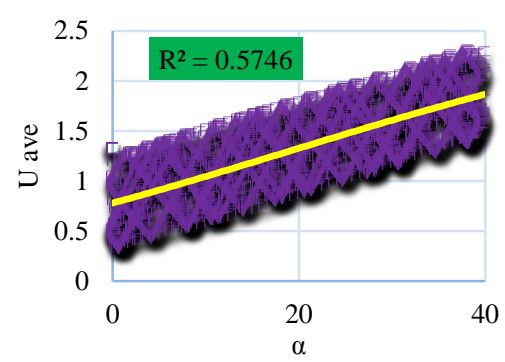

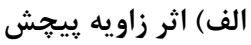

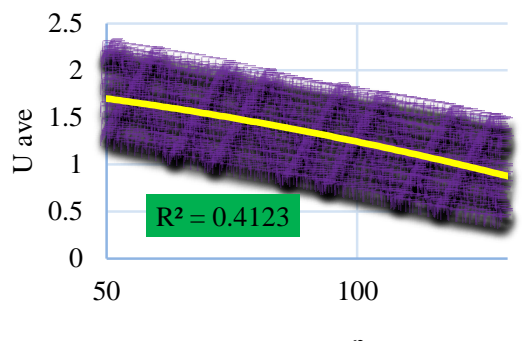

ج) اثر زاويه كانال

شكل f اثر متغيرهاى ورودى بر روى كرنش ميانغين 


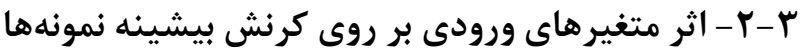

شكل ه نشان مىدهد تنها متغير اصطكاك تأثير عمدهاى بر روى ميزان كرنش بيشينه داشته است. اثر بيجشش زاويـهـ تـأثير

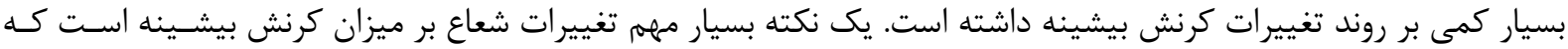

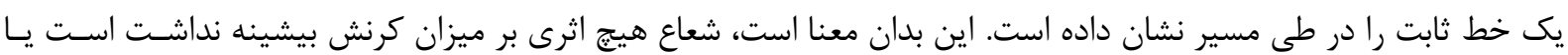

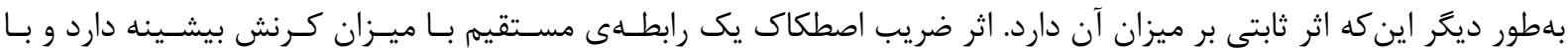

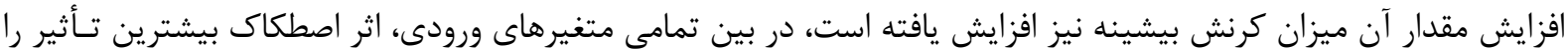

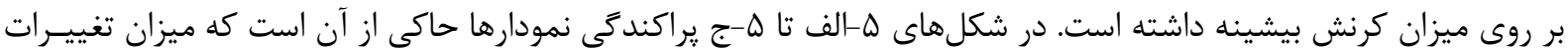

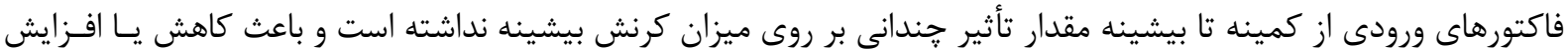

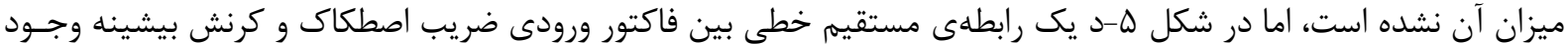

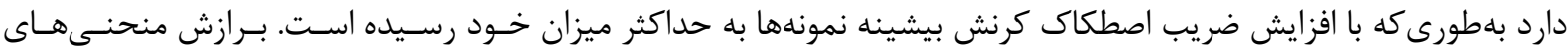

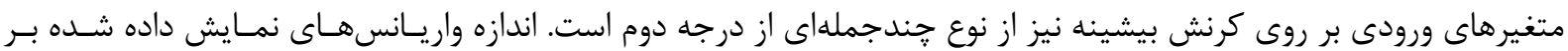

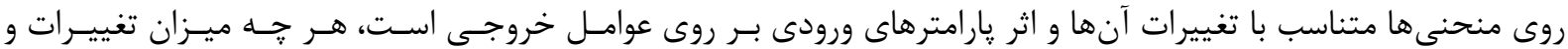

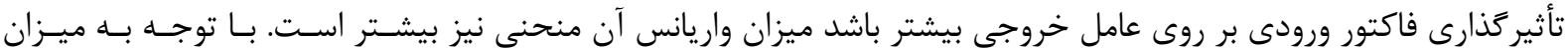

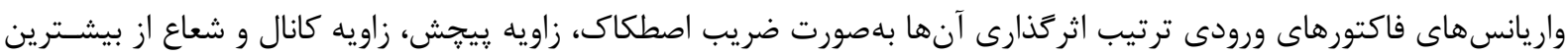

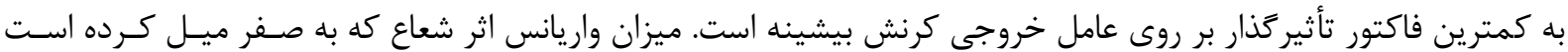

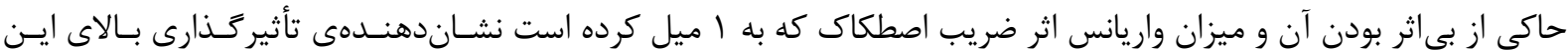
فاكتور ورودى بر روى كرنش بيشينه است.

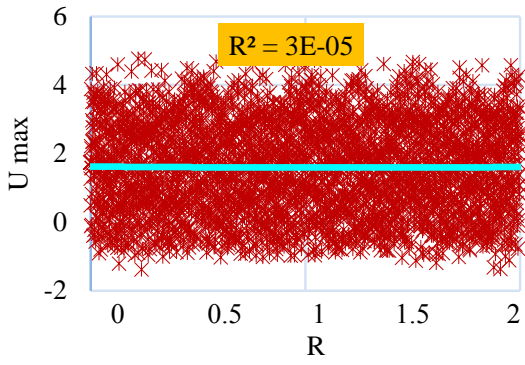

ب) اثر شعاع

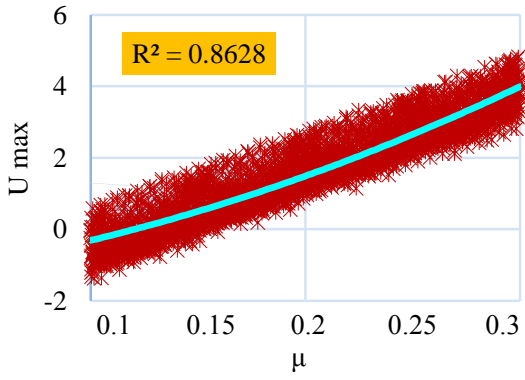

د) (1) مر ضريب اصطكاى

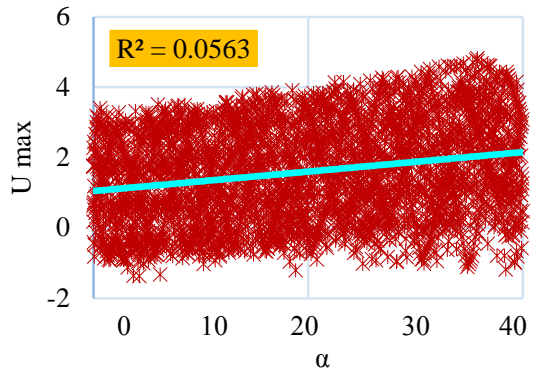

الف) اثر زاويه يِيجش

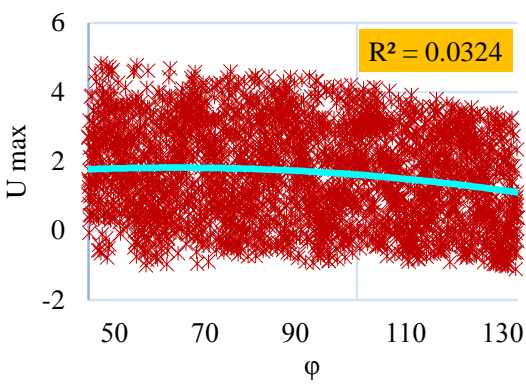

ج) اثر زاويه كانال

شكل ه اثر متغير هاى ورودى بر روى كرنش بيشينه

\section{r-r- - اثر متغير هاى ورودى بر روى نيروى بيشينه}

شكل \& روند اثركذارى متغيرهاى ورودى بر ميزان تغييرات نيروى بيشينه را نشان داده است. در مقايسه با شكل قبل و اثر

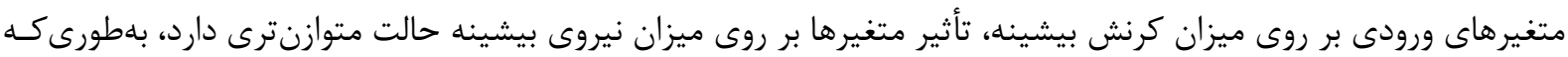




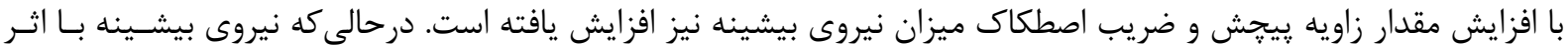

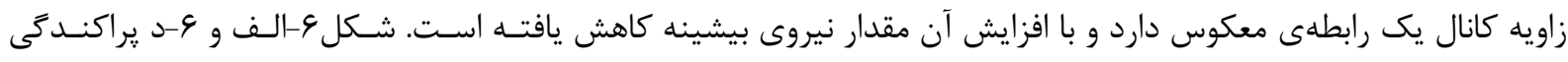

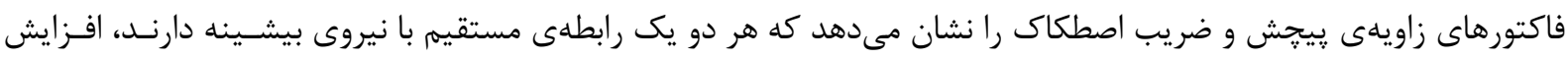

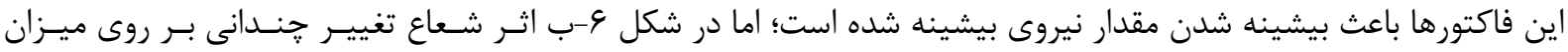

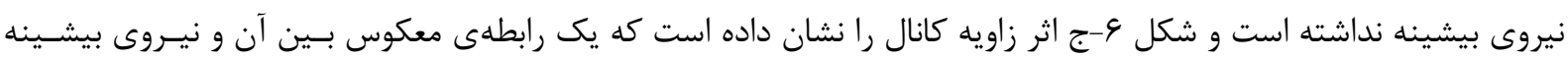

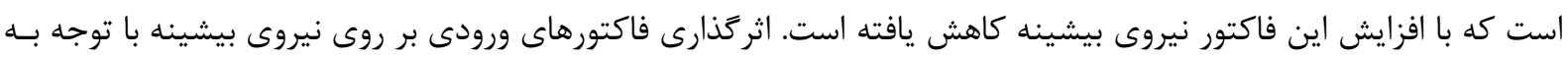

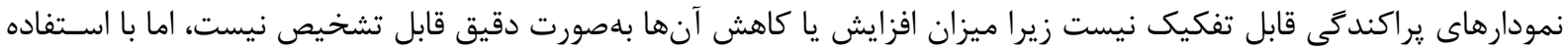

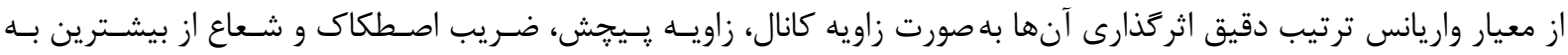

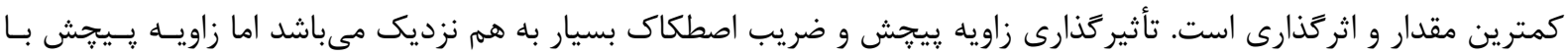

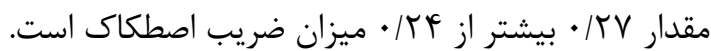

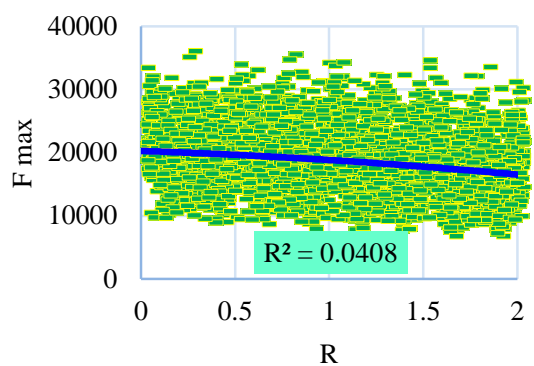

ب) اثر شعاع

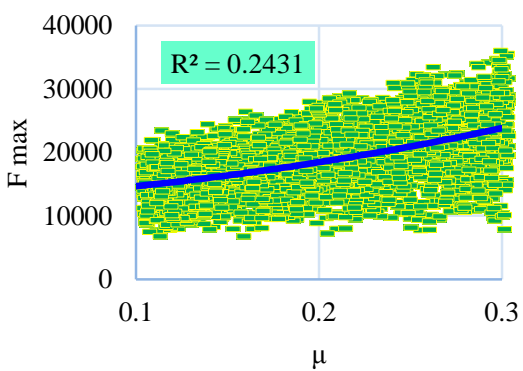

د) اثر ضريب اصطكاى

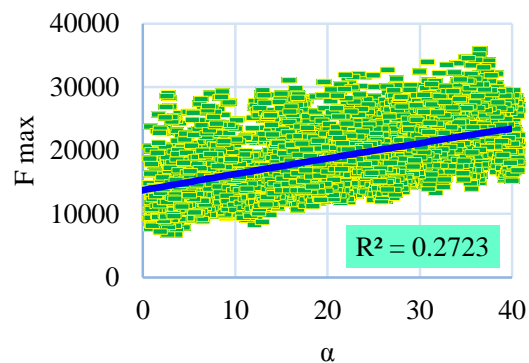

الف) اثر زاويه بييجش

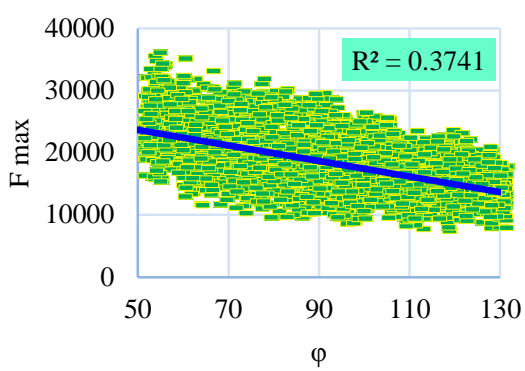

ج) اثر زاويه كانال

شكل 4 اثر متغيرهاى ورودى بر روى نيروى بيشينه

\section{r-F- ب - ب رسى كمى متغير هاى ورودى بر روى كرنش ميانگين با استفاده از روش آمارى اىفست}

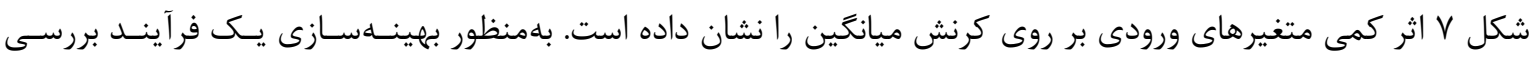

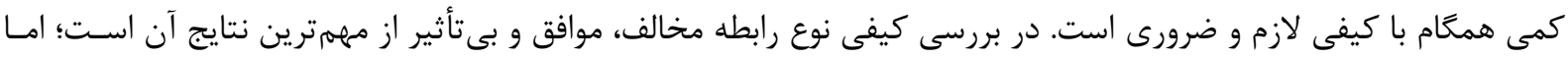

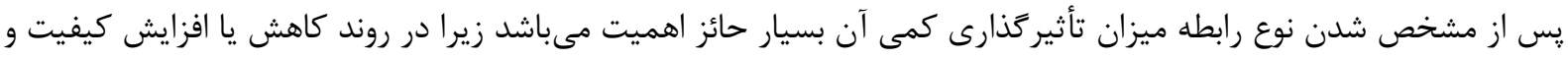

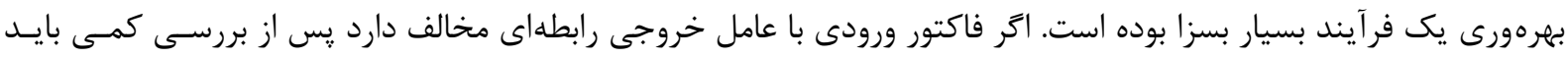

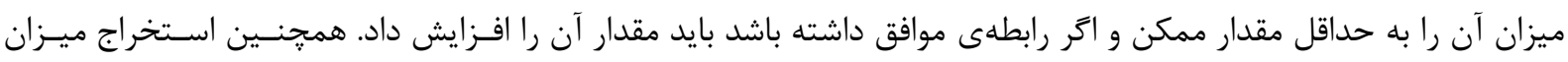

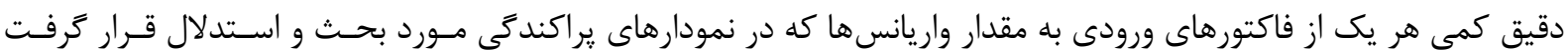

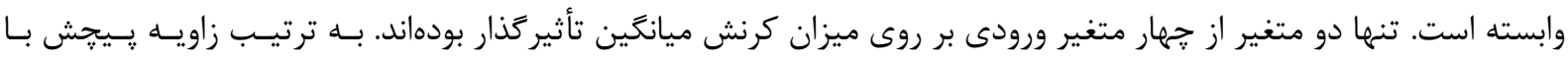

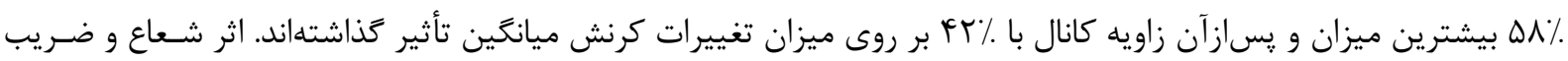

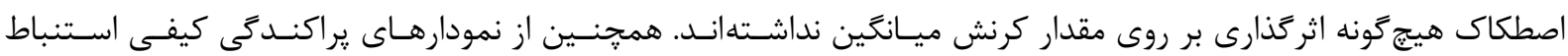

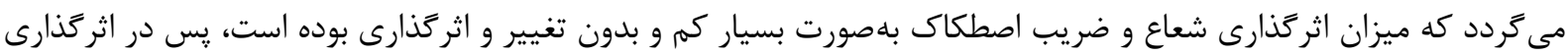




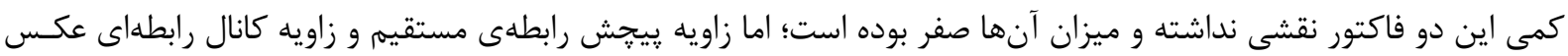

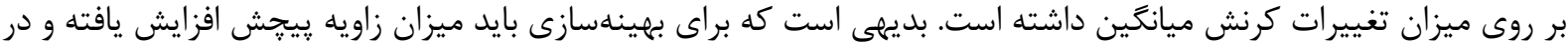

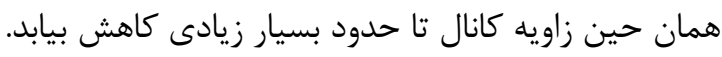

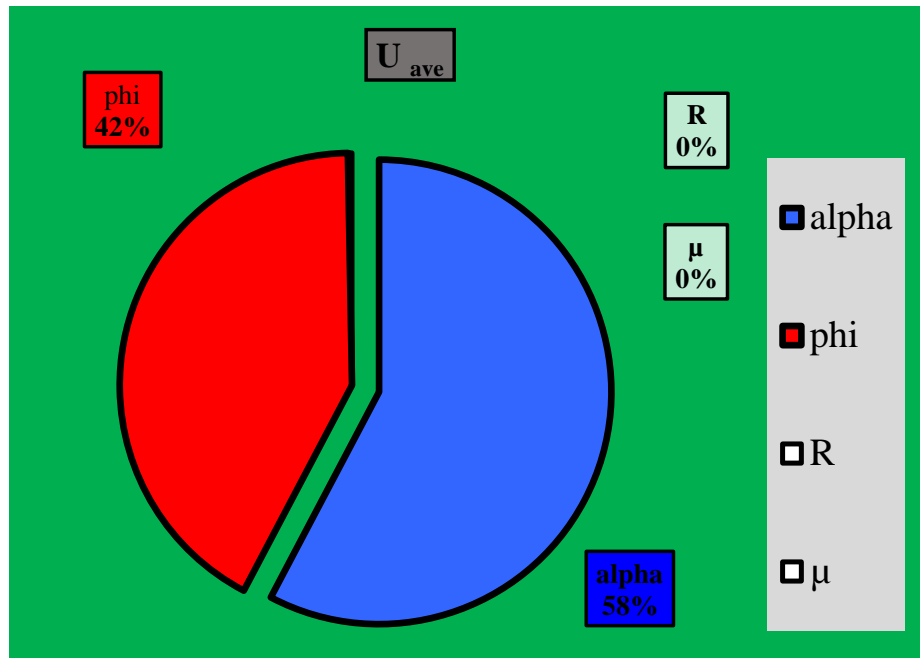

شكل V اثر كمى متغير هاى ورودى بر روى كرنش ميانكَين

r-ه- بر رسى كمى متغير هاى ورودى بر روى كرنش بيشينه با استفاده از روش آمارى اىفست

شكل 1 اثر كمى متغيرهاى ورودى بر روى كرنش بيشينه را نشان داده است. متغير ورودى اثر اصطكاك عمدهتـرين مقـدار

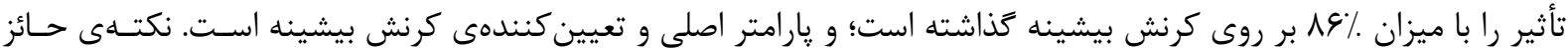

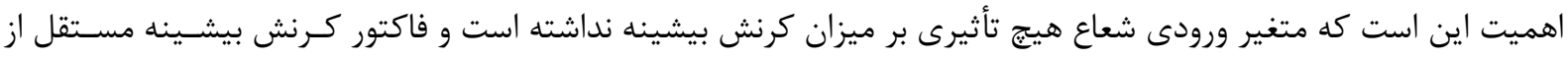

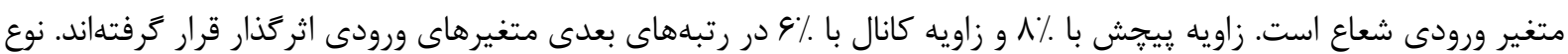

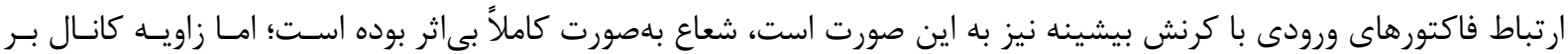

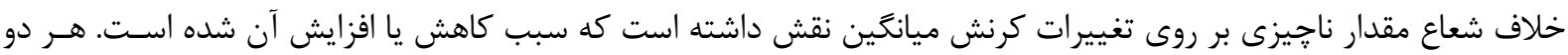

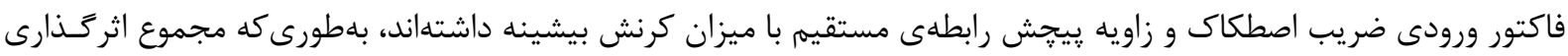
اين دو فاكتور به ميزان \% 9 است.

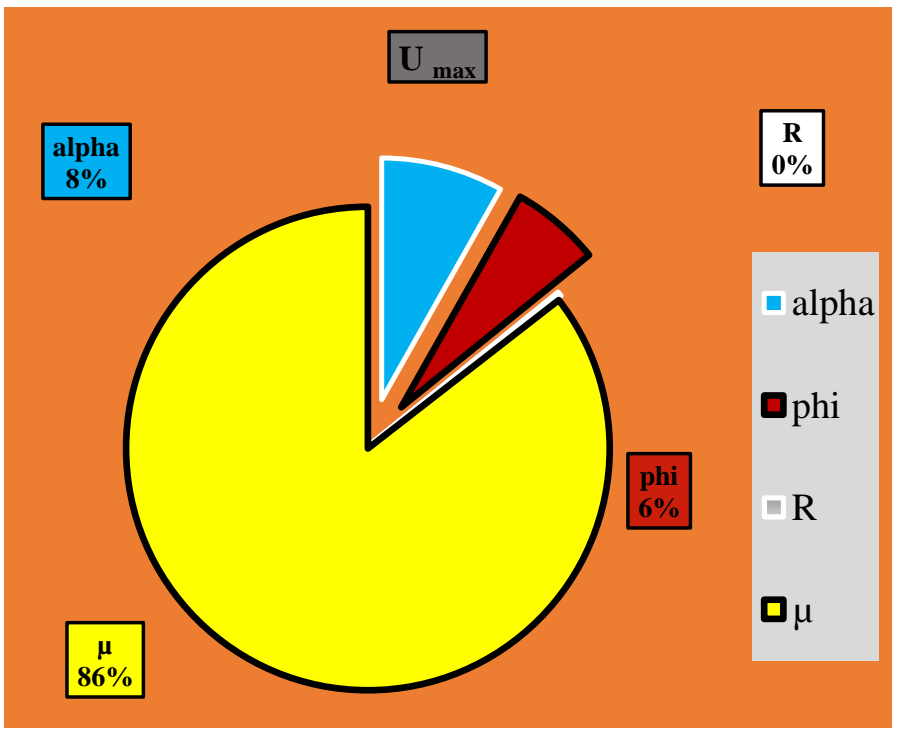

شكل ^ اثر كمى متغيرهاى ورودى بر روى كرنش بيشينه 
r-4- بر رسى كمى متغيرهاى ورودى بر روى نيروى بيشينه با استفاده از روش آمارى اىفست

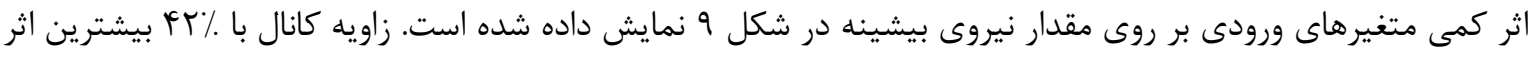

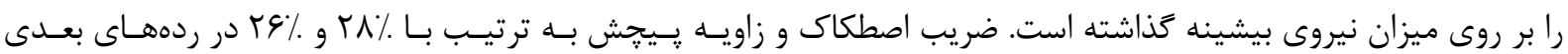

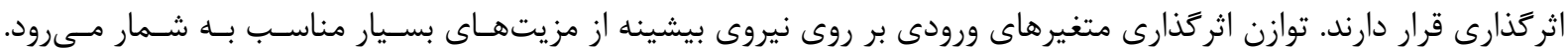

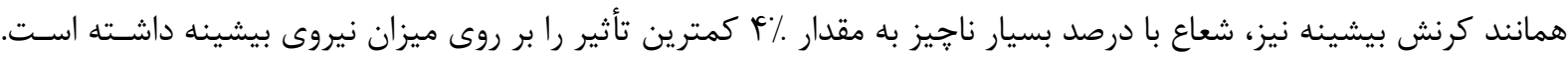

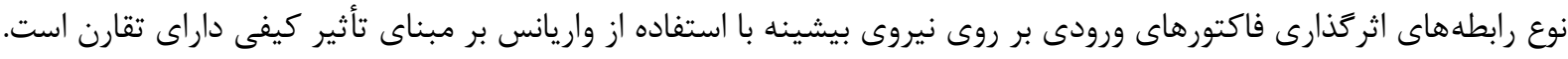

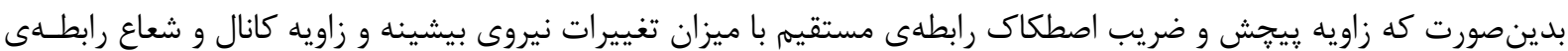

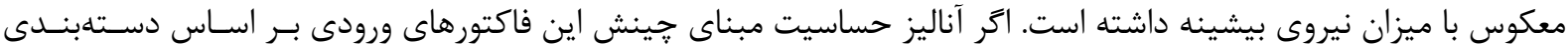

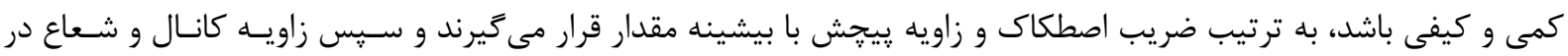

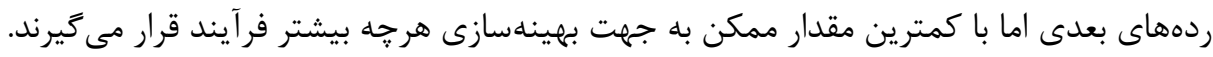

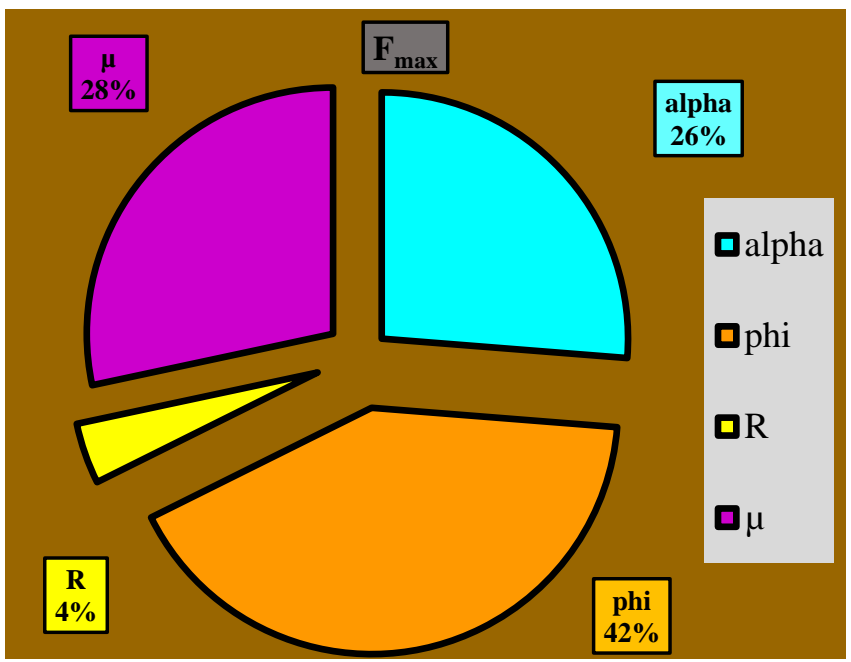

شكل 9 اثر كمى متغير هاى ورودى بر روى نيروى بيشينه

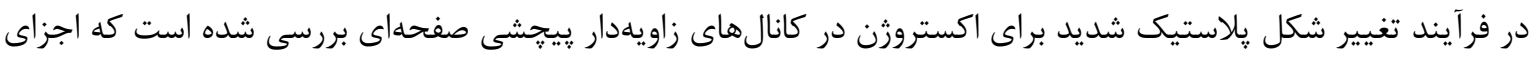

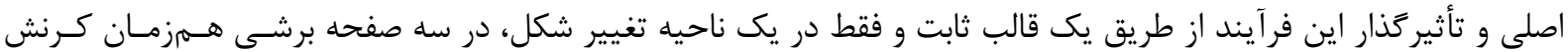

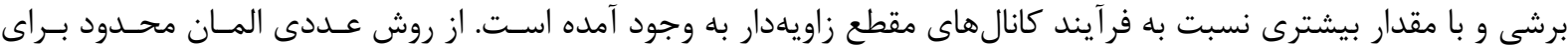

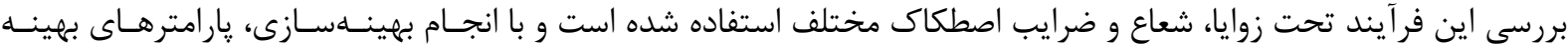

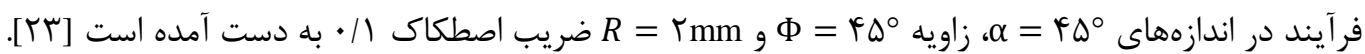

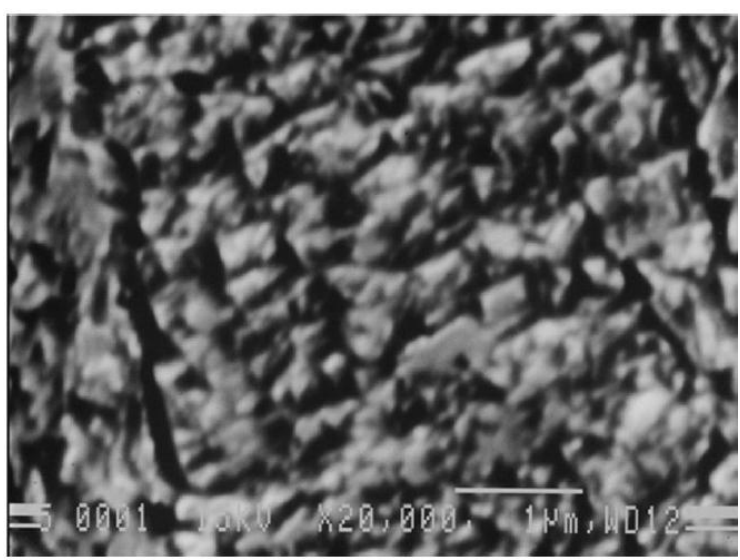

شكل Iا تصوير ميكروسكوب الكترونى روبشى نمونه فراورى شده

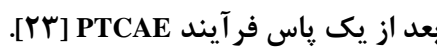

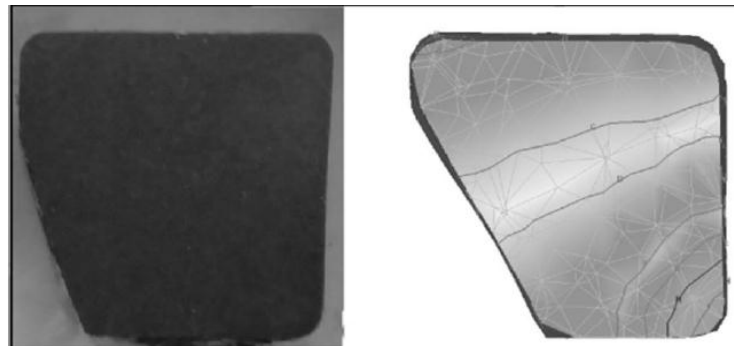

شكل •ا سطح مقطع به دست آمده از آزمايش و شبيهسازى عددى فر آيند PTCAE [TrT]. 


\section{| | - نتيجه كيرى و جمعبندى}

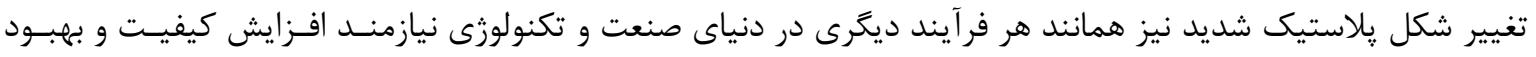

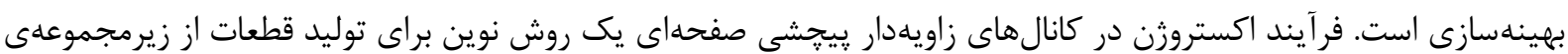

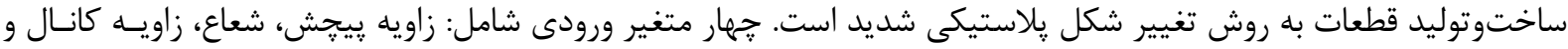

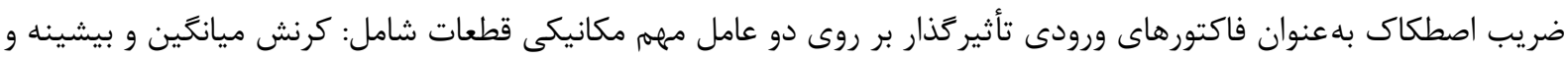

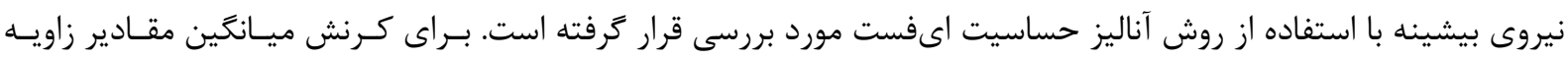

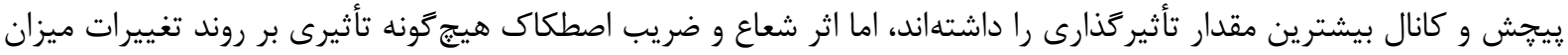

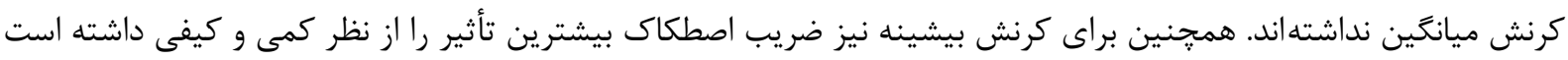

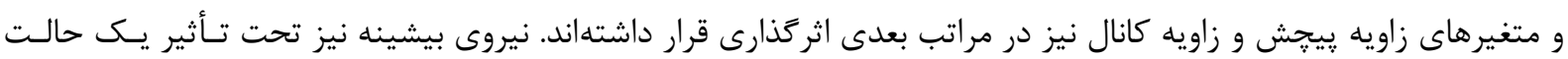

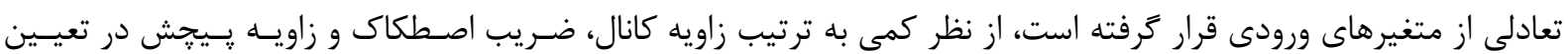

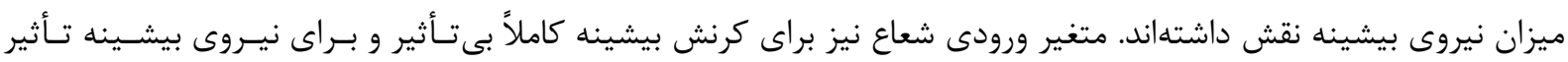

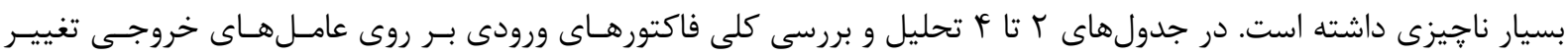

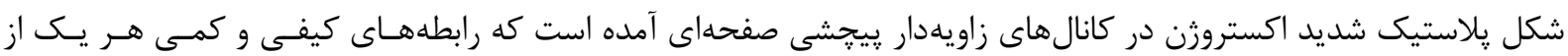
جهار فاكتور مؤثر مشخص شده است.

جدول r- تحليل و بررسى كرنش ميانغين

\begin{tabular}{|c|c|c|c|}
\hline رابطهى كمى & رابطهى كيفى & فاكتور ورودى & \\
\hline$\Delta \Lambda \%$ & مستقيم & زاويه پِيحֶ & \multirow{4}{*}{ كرنش ميانگَين } \\
\hline صفر & بدون تأثير & شعاع & \\
\hline fr\% & معكوس & زاويه كانال & \\
\hline صفر & بدون تأثير & ضريب اصطكاى & \\
\hline
\end{tabular}

جدول r تحليل و بررسى كرنش ميانغين

\begin{tabular}{|c|c|c|c|}
\hline رابطدى كمى & رابطهى كيفى & فاكتور ورودى & \\
\hline$\Lambda \%$ & مستقيم & زاويه پِيجش & \multirow{4}{*}{ كرنش بيشينه } \\
\hline صفر & بدون تأثير & شعاع & \\
\hline $4 \%$ & معكوس & زاويه كانال & \\
\hline$\wedge \varsigma \%$ & مستقيم & ضريب اصطكاى & \\
\hline
\end{tabular}

جدول F تحليل و بررسى كرنش ميانغين

\begin{tabular}{|c|c|c|c|}
\hline رابطهى كمى & رابطهى كيفى & فاكتور ورودى & \\
\hline$r \varphi \%$ & مستقيم & زاويه يِيجش & \multirow{4}{*}{ نيروى بيشينه } \\
\hline$\varphi \%$ & معكوس & شعاع & \\
\hline fr\% & معكوس & زاويه كانال & \\
\hline$r \wedge \%$ & مستقيم & ضريب اصطكاى & \\
\hline
\end{tabular}




\begin{tabular}{|c|c|}
\hline علامت اختصارى & عنوان \\
\hline$A_{j}$ & ضريب فوريه \\
\hline$B_{j}$ & ضريب فوريه \\
\hline$F_{\max }$ & نيروى بيشينه (N) \\
\hline $\mathrm{R}$ & شعاع (mm) \\
\hline$U_{\text {ave }}$ & كرنش ميانغين \\
\hline$U_{\max }$ & كرنش بيشينه \\
\hline$\alpha$ & 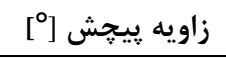 \\
\hline$\Phi$ & زاويه كانال [º] \\
\hline$\mu$ & ضريب اصطكاى \\
\hline
\end{tabular}

\section{צ- مراجع و منابع}

[1] Kleijnen J P. An overview of the design and analysis of simulation experiments for sensitivity analysis. European Journal of Operational Research. 2005;164:287-300.

[2] Félix G, Ancheyta J, Trejo F. Sensitivity analysis of kinetic parameters for heavy oil hydrocracking. Fuel. 2019;241:836-844.

[3] Dennis L, Martin O, Sonya G. DOE (Design of Experiments) in Development Chemistry: Potential Obstacles. Organic Process Research \& Development. 2001;145:324-327.

[4] Taheri M. Sensitivity analysis of 3D manipulation of spherical nanoparticles by using E-fast method. Modares Mechanical Engineering. 2018;17:59-69. (In Persian).

[5] Raab G J, Valiev R Z, Lowe T C, Zhu Y T. Continuous processing of ultrafine grained Al by ECAPConform. Materials Science and Engineering. 2004;382:30-34.

[6] Valiev R Z, Islamgaliev R K, Alexandrov I V. Bulk nanostructured materials from severe plastic deformation. Progress in materials science. 2000;45:103-189.

[7] Pouryan s, Naeini H, Safdarian R, Shirani Bidabadi B. The effect of process parameters on thinning defect in the cold roll forming process of channel section. Iranian Journal of Manufacturing Engineering. 2016;3:1118. (In Persian).

[8] Shafeie M R, Elyasi M, Hosseinzadeh M, Aghajani H, Derazkola M. Experimental Investigation of the Effect of Equal Channel Angular Pressing Intermediate Canal of on the Mechanical Properties of copper. Iranian Journal of Manufacturing Engineering. 2019;6:32-41. (In Persian).

[9] Kashfi M, Bakhtiyari D, Ghavamian A, Kashfi M, Kahal P. A numerical-experimental investigation on spring back in rectangular section thin wall hollows and extracting a relation to estimate twisted angle by considering strain harden behavior. Iranian Journal of Manufacturing Engineering. 2017;4:38-43. (In Persian).

[10] Talebi Ghadikolaee H, Elyasi M, Hosseinzadeh M. Investigate the effect of rubber layers thickness on forming of bipolar plate's microchannels in rubber pad forming process. Iranian Journal of Manufacturing Engineering. 2016;2:57-69. (In Persian).

[11] Ahmad Khan Beigi M, Shahbazi Karami J, Sheikhi. Experimental and numerical study of friction stir back extrusion process for producing ultra-fine-grained tubes. Iranian Journal of Manufacturing Engineering. 2016;3:34-44.

[12] Ghaemi Khiavi S, Emadoddin E. Plastic deformation behavior of Aluminum 5452 alloy under unconstrained high pressure torsion and effect of turns and applied pressures on their $\mathrm{r}^{*}$. Iranian Journal of Manufacturing Engineering. 2016;3:40-47. (In Persian).

[13] Alavizadeh S M, Abrinia K, Parvizi A. Twisted Multi Channel Angular Pressing (TMCAP) as a Novel Severe Plastic Deformation Method. Metals and Materials International. 2020;1:1-12.

[14] Attarilar Sh, Salehi M, Djavanroodi F. Microhardness evolution of pure titanium deformed by equal channel angular extrusion. Metallurgical Research \& Technology. 2019;116:408-418. 
[15] Amani S, Faraji Gh, Kazemi Mehrabadi H, Baghani M. Manufacturing and mechanical characterization of Mg-4Y-2Nd-0.4Zr 0.25La magnesium microtubes by combined severe plastic deformation process for biodegradable vascular stents. Proc IMechE Part B: J Engineering Manufacture. 2019;223:1196-1205.

[16] Bagherpour E, Pardis N, Reihanian M, Ebrahimi R. An overview on severe plastic deformation: research status, techniques classification, microstructure evolution, and applications. The International Journal of Advanced Manufacturing Technology. 2019;100:1647-1694.

[17] Fata A, Eftekhari M, Faraji G, Mosavi Mashhadi M. Enhanced Hot Tensile Ductility of Mg-3Al-1Zn Alloy Thin-Walled Tubes Processed Via a Combined Severe Plastic Deformation. Journal of Materials Engineering and Performance. 2018;27:2030-2337.

[18] Saltelli A, sobol I M. about the use of rank transformation in sensitivity analysis of model output. Reliability Engineering \& System Safety. 1995;50:225-239.

[19] Saltelli A, Chan K, Scott E. sensitivity analysis. Wiley series in probability and statistics, Willey, New York, 2000.

[20] Cukier R, Levine H, Shuler K. Nonlinear sensitivity analysis of multiparameter model systems. Journal of computational physics. 1978;26:1-42.

[21] Saltelli A, Tarantola V, Chan KnS. A quantitative model independent method for global sensitivity analysis of model output. Technometrics. 1999;41:39-56.

[22] Mahmoudi M, Shokuhfar A, Nakhodchi S. A new severe plastic deformation technique based on simple and pure shear. Modares Mechanical Engineering. 2016;16:145-154. (In Persian).

[23] Shamsborhan M, Moradi M, Shokuhfar A. Numerical optimization of "Planar twist channel angular extrusion" as a novel severe plastic deformation method by DOE method. Modares Mechanical Engineering. 2017;16:135-144. (In Persian).

[24] Korayem M, Zakeri M. Sensitivity analysis of nanoparticles pushing critical conditions in 2-D controlled nanomanipulation based on AFM. The International Journal of Advanced Manufacturing Technology. 2009;41:714-726.

[25] Sobol M. Sensitivity analysis for non-linear mathematical models. Mathematical modelling and computational experiment. 1993;1:407-414.

[26] Frey H, Patil S R. Identification and Review of Sensitivity Analysis Methods. Risk Analysis. 2002;22:553578. 